\title{
Concept Learning in Animals
}

\author{
Thomas R. Zentall \\ University of Kentucky \\ Edward A. Wasserman and Olga F. Lazareva \\ University of Iowa \\ Roger K. R. Thompson \\ Franklin \& Marshall College \\ Mary Jo Rattermann \\ University of Indianapolis
}

\begin{abstract}
Generally speaking, the study of concepts in cognitive psychology is anthropocentric with respect to both content and theory. A broader comparative perspective on the various forms of concept learning not only provides a more inclusive view of conceptual behavior, but it also provides a more objective perspective from which to identify underlying processes. We suggest that several of the major varieties of conceptual classes claimed to be uniquely human are also exhibited by nonhuman animals. We present evidence for the formation of several sorts of conceptual stimulus classes by nonhuman animals: perceptual classes involving classification according to the shared attributes of objects, associative classes or functional equivalences in which stimuli form a class based on common associations, relational classes, in which the conceptual relationship between or among stimuli defines the class, and relations between relations, in which the conceptual (analogical) relationship is defined by the relation between classes of stimuli. We conclude that not only are nonhuman animals capable of acquiring a wide variety of concepts, but that the underlying processes that determine concept learning are also likely to be quite similar.
\end{abstract}

Keywords: concept learning, perceptual classes, associative classes, relational classes, analogical relations

\begin{abstract}
"The proper study of mankind is man," is a popular quote, but it was written by a poet, not a scientist. The history of science offers opposing testimony... if you want to build a scientific understanding of the evolution and meaning of intelligence then you must study animals... The eventual payoff will indeed be an understanding of people as well as beasts." Staddon (p. xiii, 1983).
\end{abstract}

TRZ's research was supported by grants from the National Institute of Mental Health (MH 59194 and MH 63726) and EAW's research was supported by grants from the National Science Foundation (IBN 99-04569) and the National Institute of Mental Health (MH 47313).

Correspondence concerning this article should be addressed to Thomas R. Zentall, Department of Psychology, University of Kentucky, Lexington KY 40506-0044. Phone: (859) 257-4076 Fax: (859) 323-1979. Email: zentall@uky.edu
Few, if any, researchers studying human cognition would argue with Murphy's (2002) claim that, "Concepts are the glue that holds our mental life together ... in that they tie our past experiences together to our present interactions with the world, and because the concepts themselves are connected to our larger knowledge structures" (Murphy, 2002, p. 1). In other words, being able to sort objects, events, and relations into classes allows one to transfer learning to new stimuli or contexts that one judges to be perceptually, associatively, lexically, or functionally equivalent to those involved in the original learning.

The advantage of this conceptual ability is that it provides great efficiency to learning. If a new environment can be identified as being similar to an old one, then prior learning can be applied, thereby reducing the costs and risks associated with new trial-and-error learning. Undoubtedly, many animal species other than humans have had to cope with this 
problem of "carving nature at its joints:" detecting constancy across time and space despite the inherent variability in dynamic environments. One might reasonably suspect, therefore, that humans' conceptual abilities are neither unique nor did they arise de novo; rather, they may have clear nonlinguistic parallels and origins in other (nonhuman) animals. Yet, despite its title -- The Big Book of Concepts -- and its scholarly merits, Murphy's (2002) volume is not unusual in cognitive psychology with respect to its entirely anthropocentric perspective on concepts.

With the possible exception of developmental psychologists (see Wasserman \& Rovee-Collier, 2001), there is typically little overt interest within cognitive science in comparative analyses of the similarities and differences in conceptual behavior between humans and other animals. Why is this the case? We suspect that a major contributing factor is the lack of a common currency or terminology among the major research traditions (e.g., see Hampton, 1999) studying the 'murky' topic of concepts: a key notion for which there is no generally accepted definition (see, for example, Chater \& Heyes, 1994; Delius 1994 ; Huber, 1999; Medin \& Smith, 1984; Schank, Collins, \& Hunter, 1986; Thompson, 1995; Wasserman \& Bhatt, 1992; Zentall, Galizio, \& Critchfield, 2002). To paraphrase Winston Churchill's comment regarding the British and Americans, those who study concepts in human and nonhuman animals are, perhaps, two fields of research separated by a common language. The current divide between these research traditions in cognitive science is unfortunate, particularly with respect to the identification of what is special about human cognition independent of its lexical content.

In this paper, we attempt to redress the current anthropocentric imbalance in cognitive science with a survey of some of the work that we and our colleagues have conducted to assess the cognitive abilities of animals as phylogenetically diverse as pigeons, monkeys, apes, and humans. This research focuses on the presence, or absence, of concepts in the cognitive functioning of the animals under study. We will show that there are several instances in which the behavior of species other than humans is conceptual in nature and includes several of the major varieties that are conventionally attributed to humans alone.

We believe that a comparative perspective, as presented here, provides not only a more inclusive view of conceptual behavior, but it also provides a more objective perspective from which to identify those instances in which cognitive processes are similar in humans and nonhumans as well as those instances in which seemingly similar conceptual behavior may be mediated by decidedly different cognitive processes.
We note one important caveat: space limitations demand that our comparative survey be selective. We thus encourage readers who are interested in an even broader overview of contemporary advances in comparative cognition to refer to an increasingly available literature in comparative cognition (e.g., Bekoff, Allen, \& Burghardt, 2002; Cook, 2001; Cummins \& Allen, 1998; Fagot, 1999; Gomez, 2004; Heyes \& Huber, 2000; Lazareva \& Wasserman, in press; Mackintosh, 1994; Rogers \& Kaplan, 2004; Roitblat \& Meyer, 1995; Sternberg \& Kaufman, 2002; Shettleworth, 1998; Tomasello \& Call, 1997; Vauclair, 1996; Wasserman \& Zentall, 2006; Wynne, 2001; Zentall et al., 2002).

\section{Overview}

We will describe several of the most important kinds of concept learning for which there is considerable evidence in nonhuman animals. The first, perceptual concept learning, is the most familiar form of categorization in humans; it involves the sorting of stimuli into classes, like rocks or tables, that share one or more physical properties. We propose that perceptual similarity guides the responses of nonhuman animals as surely as it guides the speaking of humans, thus suggesting that this basic-level conceptual behavior is not unique to people. In both human and nonhuman animals, the development of perceptual concepts appears to be largely under the control of the behavioral principles of discrimination and primary stimulus generalization.

The second, associative concept learning, involves the ability of animals to form categories made up of arbitrary stimuli that are deemed to be equivalent on the basis of their being associated with a common event or outcome (e.g., in humans, an object and the word for that object). Here, the evidence suggests a qualified "yes" to the question of whether conceptual behaviors and even their underlying processes are the same in animals and people. Although nonhuman animals appear to be more limited by the directionality of their associations, those associations show clear emergent properties indicative of conceptual behavior.

The third, relational concept learning, involves the relationship between (or among) objects. One of the most basic and interesting relational concepts is sameness/difference: the ability to report that one object is either the same as or different from another. We propose that, although humans have extensive practice with relational concepts and have made them an integral part of their language, it is clear that under proper conditions animals too demonstrate a considerable ability to use relational concepts.

Finally, beyond first-order relational concepts are secondorder relational concepts, the most familiar being analogical reasoning. Analogical reasoning involves appreciating the 
relations between relations (i.e., analogies), such that one can be given two objects that have a certain relation between them (e.g., same) and be offered a choice between two other pairs of objects: one that has the same relation between them (two identical objects) and the other that has a different relation between them (two nonidentical objects). Here, perhaps one sees the first evidence of a dichotomy between behavior and process. At the behavioral level, there is good evidence of the relational capacity in nonhumans; yet, further analyses suggest a possible disparity in process between symbolsophisticated apes and humans, on the one hand, and other animals, on the other.

\section{Perceptual Classes}

Perceptual classes have inherent common properties that generally involve stimuli which share characteristics that humans would define in terms of a category label (e.g., cats, cars); for this reason, they are often called basic-level classes or concepts. However, it is often difficult to specify the particular common elements among the concept members that might be used to classify them (Smith \& Medin, 1981; see also Fetterman, 1996). For example, pictures of cats are not likely to have distinctive defining features; yet, humans generally have no difficulty correctly categorizing them. As well, we have learned that animal subjects too can readily sort such pictures into natural and unnatural categories.

\subsection{Basic-Level Categorization in Animals.}

Herrnstein and Loveland's (1964) classic work found that pigeons could discriminate $35-\mathrm{mm}$ color slides that depicted a particular class of stimuli (e.g., people) from otherwise comparable slides that did not. These discriminations not only held for large sets of previously seen slides, but they also generalized to novel slides from the feature-present and feature-absent categories. Successful stimulus generalization in projects of this sort supported Herrnstein's suggestion that perceptual concepts are open-ended and comprise limitless instances of related stimuli. Furthermore, such concept learning was not confined to stimuli with which the pigeons were likely to be familiar (e.g., trees and water); concept learning could also involve stimuli that had never been observed by the pigeons (e.g., underwater pictures of fish; for a review of this research, see Herrnstein, 1985).

A large proportion of research inspired by Herrnstein's pioneering studies continued to employ a single category (for example, fish) together with its complementary category (for example, non-fish). Both pigeons and primates were shown to be able to learn a variety of these perceptual concepts and to transfer their performance to novel instances of the concept (e.g., Aust \& Huber, 2002; Matsukawa, Inoue, \& Jitsu- mori, 2004; Schrier \& Brady, 1987; Vogels, 1999; Vonk \& McDonald, 2002; 2004).

Later, Premack (1976) suggested that, although many animals can learn such dichotomous presence/absence classifications, "only primates may sort the world, i.e., divide it into its indeterminately many classes" (p. 215). In response, Wasserman and his colleagues developed a different procedure to study the acquisition of perceptual concepts that was analogous to a parent teaching a child to name the pictures in a book.

In this "name" game, the parent opens the picture book, points to one of its many colorful illustrations, and asks the child, "What is it?" If the child makes the correct verbal response, then positive social reinforcement is provided. If the child makes the incorrect verbal response, then no positive reinforcement is provided; instead, the parent may ask the child to try again; and if this request also fails to occasion the correct verbal response, then the parent may have to supply it. Instead of requesting verbal behavior from their subjects (an obvious impossibility), the researchers asked their birds to report members of four different categories -- cats, flowers, cars, and chairs -- by pecking four circular keys surrounding a square viewing screen (Figure 1).

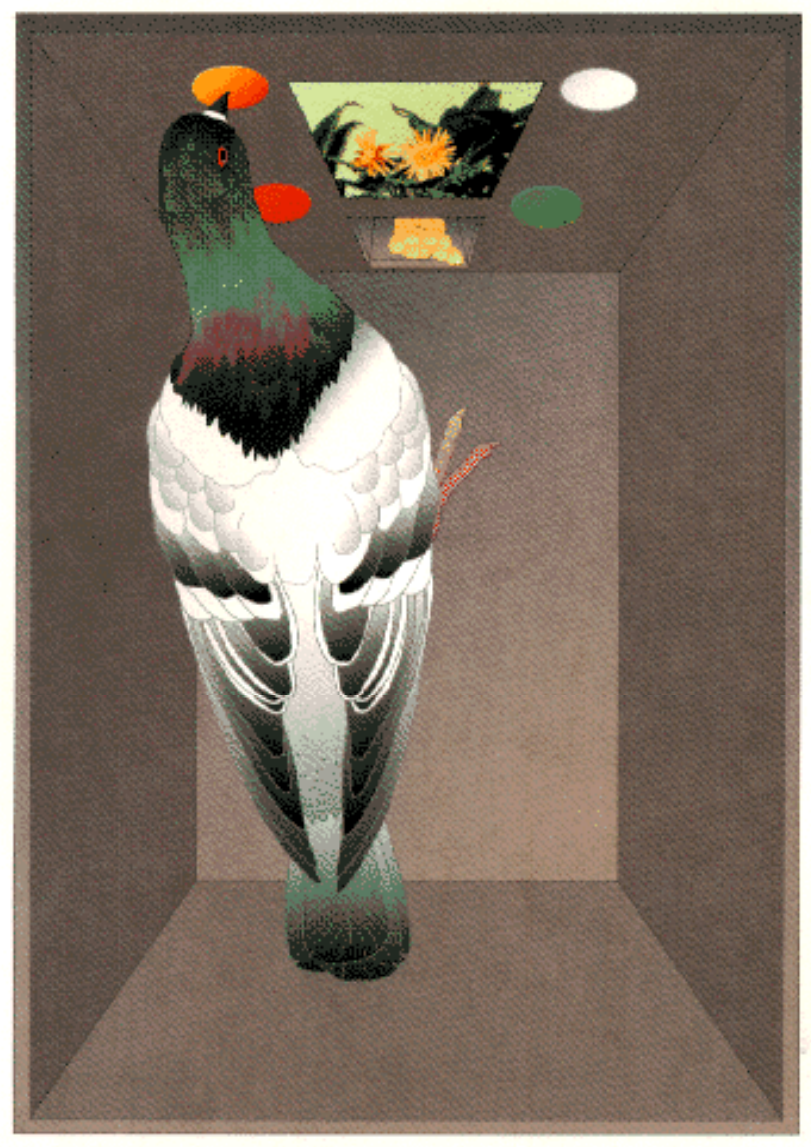

Figure 1. An overhead view of the apparatus used in the perceptual concept experiment with pigeons. 
In one experiment (Bhatt, Wasserman, Reynolds, \& Knauss, 1988; Experiment 1B), for example, pigeons were shown color slides depicting 10 different examples from each of the four categories. Within each category, the slides differed from each other in the number, size, color, brightness, orientation, location, and context of the stimulus object, to capture a broad range of category instances in those places where humans would ordinarily find them. After 30 pecks to the viewing screen, the four report keys were illuminated (each with a different color to help the pigeon to distinguish its response options) and a single choice response was permitted. A particular pigeon might have to peck the top left key in response to pictures of cats, the top right key in response to pictures of flowers, the bottom left key in response to pictures of cars, and the bottom right key in response to pictures of chairs. At no time in this experiment or in any of numerous others was there any sign that the pigeons categorized the photographs of human-made stimuli more slowly or less accurately than they categorized the photographs of natural stimuli. Immediately after reaching the $80 \%$ level of acquisition, the pigeons were given generalization testing with 10 new snapshots of objects in each of the four categories. Accuracy to the old slides averaged $81 \%$ and to the new ones $64 \%$. Thus, the pigeons had acquired highly discriminative behavior, which enabled them to categorize a set of complex and lifelike stimuli that they had seen only 30 times before and still other stimuli that they had never seen before.

It is noteworthy that categorization accuracy was reliably lower to the novel test stimuli than it was to the familiar training stimuli. This generalization decrement can be explained by a host of different theories of conceptual behavior -- from exemplar models to prototype models (Smith \& Medin, 1981; also see Astley \& Wasserman, 1992). This behavioral fact suggests that the pigeons had memorized some or all of the photographic stimuli that they had seen during training, although nothing in the training regimen required them to do so.

Further evidence for individual stimulus learning and memory comes from a later project (Bhatt, 1988; see Wasserman \& Bhatt, 1992) in which three groups of four pigeons each were given 48 daily training trials comprising: 12 copies of 1 example from the categories cat, flower, car, and chair (Group 1); 3 copies of 4 examples from the categories (Group 4); or 1 copy of 12 examples from the categories (Group 12). The speed of discrimination learning here was an inverse function of the number of examples per category. The mean numbers of days to reach a criterion of $70 \%$ accuracy on 2 successive days of training were: 6 for Group 1, 11 for Group 4, and 22 for Group 12. Either the smaller number of stimulus repetitions or the greater number of stimuli to be remembered with increasing numbers of examples per cat- egory can account for this learning function.

Of additional importance were the results of a generalization test with 32 novel stimuli: 8 from each category. Here, accuracy was a direct function of the number of examples in training. The mean percentages of correct choices on generalization test trials were: $27 \%$ for Group 1, $45 \%$ for Group 4 , and $62 \%$ for Group 12. Thus, although increasing the difficulty of original learning, greater numbers of training examples per category enhanced the accuracy of generalization performance, perhaps because of the increased likelihood that any given test stimulus resembled one or more of the remembered training stimuli (Smith \& Medin, 1981). Not only are these learning and testing data orderly, but they neatly correspond with categorization in humans (reviewed by Homa, Burruel, \& Field, 1987) and with discrimination performance in pigeons involving bird and mammal sketches (Cook, Wright, \& Kendrick, 1990).

All of the research described so far has entailed stimuli that were repeated, either between daily sessions or both between and within daily sessions of training. Is such stimulus repetition necessary to support successful discrimination learning and generalization? To investigate this issue, a large library of snapshots was created from four categories: people, flowers, cars, and chairs (Bhatt et al., 1988; Experiment 3). With 2,000 snapshots (500 from each of the four categories) and 40 trials per session, the pigeons could be trained for 50 sessions with no stimulus ever being repeated; each trial was thus both a training trial and a testing trial. The results of the experiment were clear-cut: pigeons came to respond discriminatively to stimuli from the four different categories of pictures even when those individual examples were never repeated. After beginning at the chance level of $25 \%$, discrimination accuracy of a group of four pigeons rose to a mean level of $70 \%$ over Days 41 to 50 of training.

The prior experiment convincingly showed that stimulus repetition was not necessary for categorical discrimination learning. The next experiment (Bhatt et al., 1988; Experiment 4) more systematically investigated the matter. Here, a set of 40 slides, 10 each from the categories person, flower, car, and chair, was chosen randomly from our library of 2,000 . Four different pigeons were trained with this set of slides on repeating sessions that alternated with nonrepeating sessions, in which the birds were trained with new sets of slides that were never used again in another session. So, the pigeons were trained with the repeating 40-slide set on Days $1,3,5, \ldots 95$ while being trained with the novel non-repeating slide sets on Days 2, 4, 6, ..96. The results clearly showed that discriminative responding rose faster and attained higher final levels of accuracy to the repeating slide set than to the nonrepeating slide sets. Performance on the repeating set rose from a mean of $29 \%$ in the first 4-day block to a mean of 
$85 \%$ in the last 4-day block; performance on the non-repeating sets rose from a mean of $26 \%$ in the first 4-day block to a mean of $66 \%$ in the last 4-day block. Although unnecessary for categorical discrimination learning, stimulus repetition facilitates the process by allowing the pigeon to use its memory for the outcome of responding on prior presentations of individual slides.

\subsection{Do Animals Perceive Perceptual Similarity Among the Members of Basic-Level Categories?}

Given all of the above data on conceptual discrimination and generalization in pigeons, one might wonder whether the differential reinforcement that was so assiduously administered in those experiments really created the conceptual behavior that the pigeons exhibited. This point may appear to be an odd one to raise, but Herrnstein and de Villiers (1980) speculated that differential reinforcement may not produce, but merely disclose already-existing concepts: "Something in the pigeon's perceptual dynamics ties [stimuli] together as a class, prior to differential reinforcement (p. 87)." This argument is tantamount to saying that primary stimulus generalization is the root of conceptual behavior, an assertion for which there is substantial empirical support in both human and nonhuman animals (Harnad, 1987).

It seems quite reasonable to hypothesize that many, if not most, basic-level human conceptual categories comprise highly similar stimuli. To our eyes, cats resemble one another much more than they resemble flowers, cars, or chairs. This perceptual similarity may be an important and inborn factor responsible for the emergence of the very concepts that we are considering, a possibility stated most clearly and emphatically by Quine (1969):

If then I say that there is an innate standard of similarity, I am making a condensed statement that can be interpreted, and truly interpreted, in behavioral terms. Moreover, in this behavioral sense it can be said equally of other animals that they have an innate standard of similarity too. It is part of our birthright. And, interestingly enough, it is characteristically animal in its lack of intellectual status ( $p$. 11).

Quine (1969) went on to suggest that the origin of perceptual similarity as well as the concordance of similarity relations from person to person is due to the operation of evolutionary mechanisms. "If people's innate spacing of [perceptual] qualities is a gene-linked trait, then the spacing that has made for the most successful inductions will have tended to predominate through natural selection ( $\mathrm{p}$. 13)." Anderson (1991) later expanded on Quine's thesis and proposed that the main force behind perceived similarity is physical similarity. In his words, "the mind has the structure it has because the world has the structure it has (p. 428)."

Quite apart from the origins of perceived similarity (Spinozzi, 1993), one can ask, is such categorical similarity perceived by nonhuman animals? And, if it is, then how can one tell? To answer these questions, several different lines of inquiry were pursued, each suggesting that animals similarly group stimuli into coherent categories without ever being required to do so by the prevailing contingencies of reinforcement.

In one such experiment, a chimpanzee was shown a picture on a screen. To keep viewing the same picture, it had to touch a response key repeatedly; otherwise, a new picture was presented (Fujita \& Matsuzawa, 1985). Analysis of the intervals between responses and the duration of responses revealed that the chimpanzee preferred to view photographs containing people; it rarely pressed the key to repeat photographs that did not contain people.

In another experiment (Sands, Lincoln, \& Wright, 1982), rhesus monkeys were trained to move a lever in one direction if two successively shown pictures were identical and to move the lever in a different direction if the pictures were non-identical. The set of pictures included six different exemplars of human faces, monkey faces, trees, flowers, and fruits. If the monkeys perceived members of the same category (for example, fruit) to be more similar to each other, then they should have been more likely to erroneously respond "same" when a picture of an apple was followed by a picture of an orange than when it was followed by a picture from another category (for example, an oak). Analysis of confusion errors found this pattern to be the case: all pictures of fruit fell into the same region of a two-dimensional similarity space. Interestingly, pictures of monkey faces and human faces were clustered together, as were pictures of trees and flowers, suggesting that rhesus monkeys viewed monkey faces as being similar to human faces and that they viewed trees as being similar to flowers.

Wasserman et al. (1988, Experiment 2) examined the coherence of categories and their concordance in pigeons and people by comparing the relative speeds of pigeons' learning to sort the same pictorial stimuli into human conceptual categories (true categorization) or into absolutely arbitrary collections (pseudo-categorization). If all of the slides in the total pool of cat, flower, car, and chair stimuli were equally discriminable from one another, then pigeons trained on the true categorization task should learn at the same rate as pigeons trained on the pseudo-categorization task, in which equal numbers of cats, flowers, cars, and chairs are associated with the four different key-peck responses. However, if, to pigeons, members of the human conceptual categories more closely resemble one another than they resemble members 
of the other conceptual categories, then learning of the true categorization task should proceed faster than learning of the pseudo-categorization task. This prediction follows from the fact that correct responding in the true categorization task should be bolstered by direct strengthening of responding to a particular key in the presence of a particular stimulus and by indirect strengthening due to similar stimuli in the same category occasioning the same response. But, in the pseudocategorization task, correct responding will be bolstered primarily by direct strengthening of responding to a particular key in the presence of a particular stimulus; greater generalization within the conceptual categories here should produce an equal likelihood of pecking all four keys, thus decreasing the accuracy of discriminative performance.

The investigation comparing these two conditions (Wasserman et al., 1988, Experiment 2) unequivocally supported the latter possibility. Over Days 37 to 40 of discrimination training, pigeons on the true categorization task averaged $79 \%$ correct, whereas pigeons on the pseudo-categorization task averaged only $44 \%$ correct. These results (and those of Edwards \& Honig, 1987, Herrnstein \& de Villiers, 1980, and Pearce, 1988) implicate differential within- versus betweenclass generalization as a key feature of visual categorization in animals.

Wasserman et al. (1988, Experiment 2) used a new technique to explore the stimuli that to pigeons constitute a class or category of objects. In any particular 40-trial session, pigeons were given a split-category discrimination, in which they viewed 20 cat slides and 20 flower slides (or 20 cat slides and 20 chair slides, or 20 car slides and 20 flower slides, or 20 car slides and 20 chair slides). For each pigeon, half of the cat slides required a peck to one key (Key 1) and the other half of the cat slides required a peck to a second key (Key 2), whereas half of the flower slides required a peck to a third key (Key 3) and the other half of the flower slides required a peck to a fourth key (Key 4). (Cat-chair, car-flower, and car-chair sessions were similarly constructed, with different pigeons having different key assignments). If the cat slides in the first set were equivalently discriminable from the 30 other slides shown in the illustrative session, then errors should be randomly distributed to Keys 2, 3, and 4. However, if the 10 slides in the first set of cats are more similar to the 10 slides in the second set of cats than they are to the 20 flower slides, then more errors should be made to Key 2 than to Keys 3 or 4 . The pigeons' pattern of errors was clearly consistent with the latter possibility. Over Days 105 to 112 of training, a mean of $56 \%$ of all errors were withincategory in nature (33\% was the chance level of errors, since there were three keys on which errors could be made).

A final experiment (Astley \& Wasserman, 1992; Experiment 2), provides perhaps the most direct evidence on the perceived similarity of category members. There, pigeons learned a successive go/no go discrimination with 60 slides: $12 \mathrm{~S}+$ stimuli and $48 \mathrm{~S}$ - stimuli. All eight birds were given the same S- stimuli: 12 people, 12 flowers, 12 cars, and 12 chairs. Different birds had different S+ stimuli: a given bird's S+ stimuli might be 12 different people, 12 different flowers, 12 different cars, or 12 different chairs. Assuming that the $12 \mathrm{~S}+$ stimuli are equally similar to all $48 \mathrm{~S}$ - stimuli, errors should be randomly distributed among the four $S$ - categories, including the one from which the $\mathrm{S}+$ stimuli were picked. But, if, to pigeons, members of a given human conceptual category more closely resemble one another than they resemble members of different conceptual categories, then errors should be nonrandomly distributed and should be disproportionately committed to the $\mathrm{S}$ - stimuli from the same category as the $\mathrm{S}+$ stimuli.

In fact, errors were notably nonrandom, regardless of whether the S+ stimuli were slides of people, flowers, cars, or chairs. Over all 16 days of multiple schedule training and all eight pigeons, a mean of $43 \%$ (rather than the chance mean of $25 \%$ ) of all S- errors were committed to stimuli from the $\mathrm{S}+$ category. This experiment thus reveals that pigeons group similar stimuli together, even when that grouping is unrelated to the prevailing contingency of reinforcement. Unlike the initial studies that first explicitly reinforced correct categorization responses and later found reliable generalization to untrained instances, categorical generalization here was shown by the birds' untrained propensity to spontaneously commit the most errors to negative discriminative stimuli from the same conceptual category as the positive discriminative stimuli. A strong perceptual basis for conceptualization is clearly implicated by the results of this study.

\subsection{Summary}

The research reviewed in this section strongly suggests that nonhuman animals very ably master perceptual or basiclevel concepts. Such mastery appears to rely on the familiar behavioral principles of discrimination and primary stimulus generalization. The roots of conceptualization thus appear to lie deep in the perceived similarity of external stimuli. Differential similarity influences the responses of nonhuman animals in much the same way as it influences the speaking of humans. Although it may not always be the case that humans and nonhuman animals categorize stimuli in the same way (see Roberts \& Mazmanian, 1988; Yoshikubo, 1985; Fujita, 1987), based on the results presented here, one can conclude that both conceptual behavior and its underlying cognitive processes are generally similar in humans and nonhuman animals.

\section{Associative Classes}

As noted above, the members of a perceptual class share 
common physical characteristics. In contrast, for associative classes, the basis for the common response to members of the class is arbitrary and associative. The flexibility of associative classes can readily be seen in the extent to which they are used in human language. An associative class may consist of an object and its various symbolic representations. For example, the object itself, chair, the spoken word "chair," and the written word CHAIR are all members of a common associative class. The utility of an associative class lies in the fact that one member of the class can represent the others. The ability of a word to serve as the symbolic representation of an object provides humans with the remarkable ability to refer to an object that is not currently present.

An important characteristic of an associative class is the ability of a symbolic representation to take on newly acquired attributes of an object. For example, to a young child, the word "dog" may represent an animal having the properties 'friendly,' 'wags its tail,' and 'licks one's face;' but, if the child has an unhappy experience with a dog that growls and lunges toward the child in the apparent defense of its territory, the child may add to its representation of dog the attribute 'may be aggressive.' If the animal and the word "dog" belong to the same associative class, then without further training, the word "dog" should elicit some of the same anxiety that has been newly associated with the animal itself. In other words, having had such an aversive experience with a dog, the child's reaction to her mother's suggestion, "Let's go visit Jimmy's new dog," should elicit more anxiety than it would have before the aversive experience.

Other examples of associative classes come from superordinate categories (i.e., categories constructed from several basic-level categories). For example, the category animal may include images of birds, mammals, and insects. Although not considered here in detail, there is clear evidence in both primates and birds that these animals can categorize photographic stimuli at the superordinate level (Lazareva, Freiburger, \& Wasserman, 2004; Roberts \& Mazmanian, 1988; Wasserman, DeVolder, \& Coppage, 1992; Vonk \& McDonald, 2004).

\subsection{Establishing Associative Classes: Many-To-One Map- ping}

Associative classes can be established in both humans and nonhumans by the common mapping of stimuli in conditional discriminations (matching-to-sample). In a conditional discrimination, an initial or sample stimulus indicates which of two comparison stimuli is correct. For example, if the sample is a red light, then the large circle is correct, whereas if the sample is a green light, then the small circle (or dot) is correct. If more than one sample is associated with the same comparison, then the discrimination is called many-to-one matching. So, in addition to the preceding associations, if the sample is a vertical line, then the large circle is correct, whereas if the sample is a horizontal line, then the dot is correct. Although red and vertical line are each separately paired with the circle, their membership in a common class can be shown by an independent test.

As in the case of the dog acquiring new characteristics for the child and then the child demonstrating that those characteristics were also acquired by the word "dog," we could ask if new associations acquired by a nonhuman animal during interpolated training between one pair of the original samples (e.g., red and green) and a new pair of comparisons (e.g., blue and white) would transfer to the remaining samples (i.e., vertical and horizontal lines) on special test trials. The design of this experiment is presented in Table 1 .

Most of the pigeons in this experiment (Urcuioli, Zentall, Jackson-Smith, \& Steirn, 1989) showed evidence of emergent relations between the line-orientation samples from original training and the comparisons from interpolated training (i.e., the pigeons treated the line samples in much the same way they had learned to treat the red and green samples). The results of this experiment are presented in Figure 2 (also see Wasserman, DeVolder, \& Coppage, 1992).

Although one could describe these results in terms of emergent stimulus relations, it may have more heuristic value to suggest that the pigeons commonly represented the samples

\section{Table 1. Common coding: Many-to-one transfer design}

\begin{tabular}{llll} 
Group & Phase 1 & Phase 2 & Test \\
\hline Consistent & R-V & R-C & \\
& G-H & G-D & \\
& V-V & & V-C \\
& H-H & & H-D \\
Inconsistent & R-V & R-C & \\
& G-H & G-D & \\
& V-V & & V-D \\
& H-H & & H-C \\
\hline
\end{tabular}

Note. $R=$ red, $G=$ green, $V=$ three vertical black lines, $H=$ three horizontal black lines, $C=a$ white line-drawn circle, $D=a$ white dot. All lines and shapes were projected on a black background. For each trial type, the first letter represents the sample and the second the correct comparison. In test, samples from Phase 1 that were not presented in Phase 2 were presented with the comparisons from Phase 2 and reinforced responding was either consistent with or inconsistent with the presumed common representations (after Urcuioli et al. 1989). 


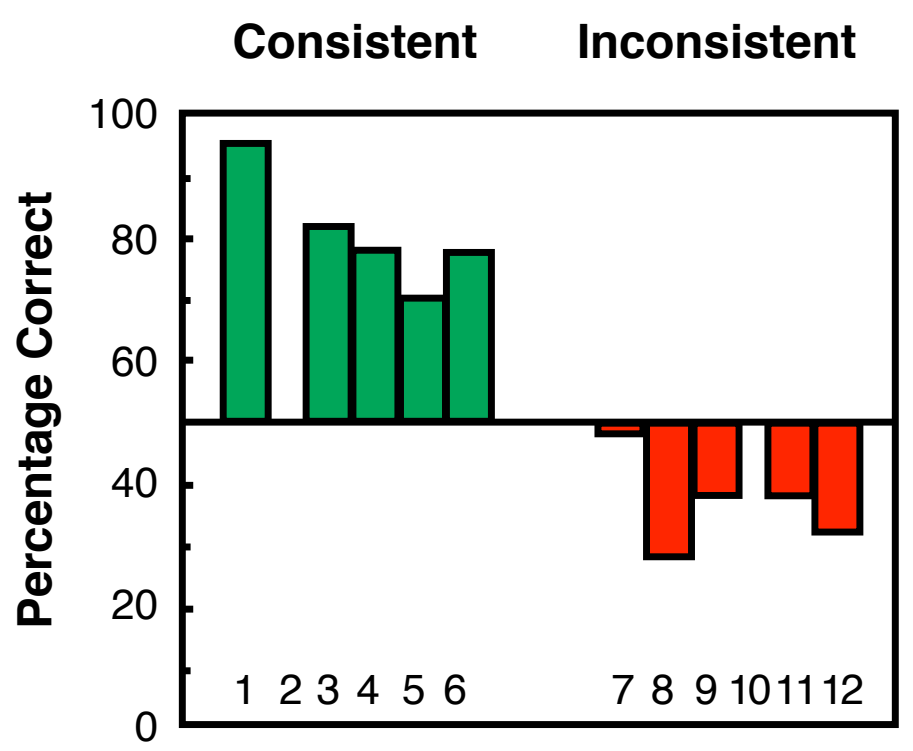

\section{Transfer Data for Each Subject}

Figure 2. Transfer of training involving emergent relations consistent and inconsistent with presumed associative stimulus classes developed during many-to-one training (Adapted from Urcuioli, Zentall, Jackson-Smith, \& Steirn, 1989).

that were associated with the same comparison stimulus. In other words, it may be that many-to-one training alters the representation of samples that are associated with the same comparison. To test this common coding hypothesis, Zentall and his associates conducted a series of experiments to discover convergent evidence for the existence of common representations.

Consistent with the common coding hypothesis, Kaiser, Sherburne, Steirn, and Zentall (1997) found that it was more difficult for pigeons to learn to discriminate between samples associated with the same comparison stimulus than between samples associated with different comparison stimuli. In this experiment, following training on many-to-one matching, pigeons were trained on a simple successive discrimination involving the four samples (see Table 2). When samples associated with the same comparison during original training were both trained as positive stimuli or were both trained as negative stimuli during successive discrimination training, acquisition of the successive discrimination was rapid. But, when samples associated with the same comparison during original training were treated differently during successive discrimination training, such that one was positive and the other negative, acquisition was significantly slower (see Figure 3). The results of experiments with human participants also support the common coding hypothesis (Delamater \& Joseph, 2000).

When a delay is inserted between the sample and comparison stimuli and that delay is varied between trials, one
Table 2. Sample Discriminability Design

\begin{tabular}{ccc} 
Train & \multicolumn{2}{c}{ Transfer } \\
\hline & Consistent & Inconsistent \\
\cline { 2 - 3 } R-C & R+ & R+ \\
G-D & G- & G- \\
V-C & V+ & V- \\
H-D & H- & H+ \\
\hline
\end{tabular}

Note. $R=$ red, $G=$ green, $V=$ three vertical black lines, $H$ $=$ three horizontal black lines, $C=$ a line-drawn circle, $D=$ a $2 \mathrm{~mm}$ dot. All lines and shapes were projected on a black background. For each trial type the first letter represents the sample and the second the correct comparison. The transfer test for Group Consistent consisted of simple successive discrimination in which the samples presumed to represent one stimulus class were discriminated from the samples presumed to represent the other stimulus class. The tran sfer test for Group Inconsistent consisted of a similar simple successive discrimination but one sample from each presumed stimulus class had to be discriminated from the other sample in its presumed class.

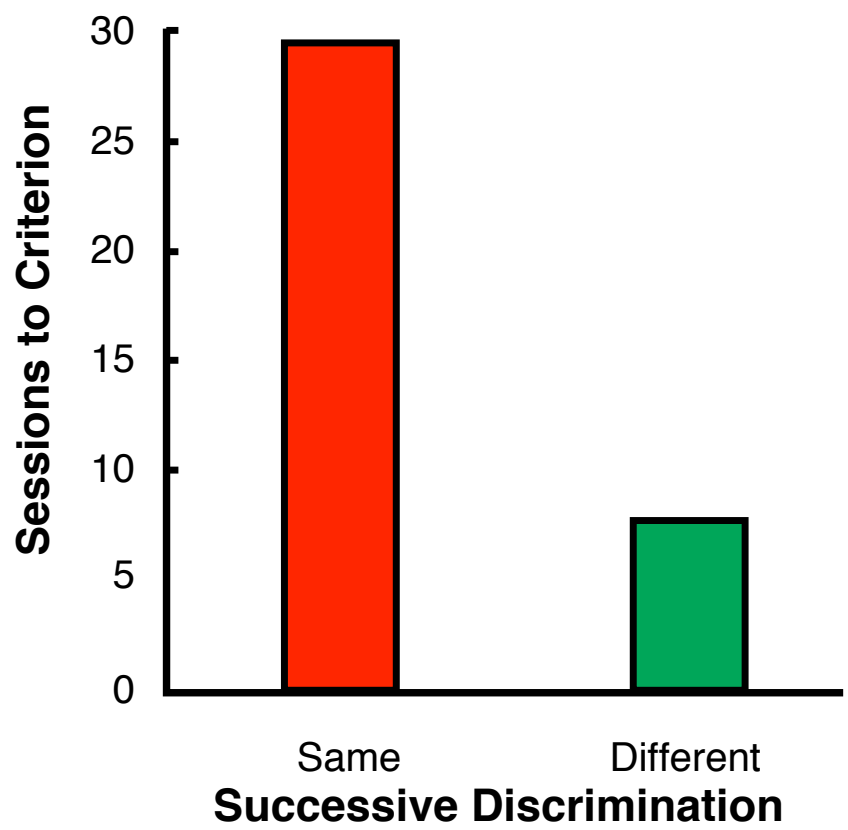

Figure 3. Acquisition of simple successive discriminations involving samples following many-to-one matching training. Discriminating between samples from the same presumed category (Same) was harder than between samples from different presumed categories (Different) (adapted from Kaiser, Sherburne, Steirn, \& Zentall, 1997). 
can plot matching accuracy as a function of the duration of the delay. The resulting retention function can provide suggestive evidence for the nature of the underlying representation. For example, following matching-to-sample training with hue samples, the retention functions for pigeons are generally much shallower than they are following line-sample training (Farthing, Wagner, Gilmour, \& Waxman, 1977; Urcuioli et al., 1989; Zentall, Urcuioli, Jagielo, \& JacksonSmith, 1989). However, hue and line samples that are associated with the same comparison result in retention functions on line sample trials that are quite similar to those on hue sample trials (see Figure 4; Urcuioli et al., 1989; Zentall et al., 1989), a finding which suggests that the samples have a common representation.

\subsection{What is the Nature of the Common Representation?}

The research on associative classes described to this point provides evidence for the pigeons' common representation of samples associated with the same comparison. However,

\section{One-to-One Matching}

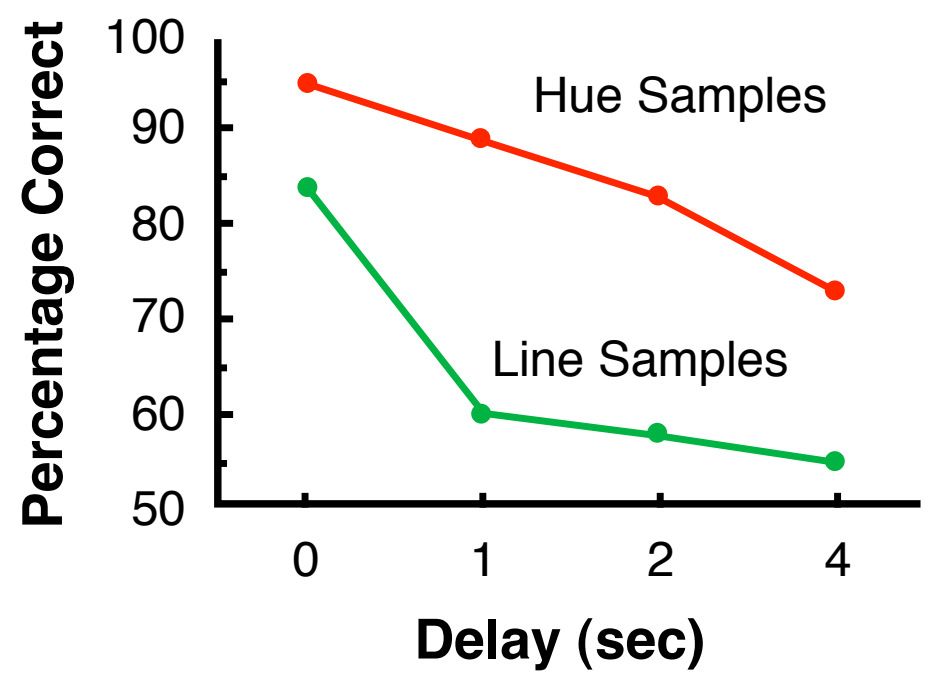

presentation of one of the samples, say A, activates a representation of the other sample, $\mathrm{B}$, a transformed retrospective representation of the original stimulus. Thus, the common representation may be either a prospective representation of the expected correct comparison stimulus or a retrospective representation of the recently seen sample (Honig \& Thompson, 1982).

Urcuioli (1996) proposed that a common prospective code in the form of a response intention can account for the transfer of training results reported by Urcuioli et al. (1989) via response mediation (see Table 3). The procedure consisted of two training phases and a testing phase. In Urcuioli's model, in Phase 1, many-to-one matching training results in, for example, red and vertical-line samples each evoking a representation of the correct comparison stimulus (e.g., circle). Then, during interpolated training in Phase 2, presentation of the red sample continues to evoke a representation of the circle comparison and that representation becomes

\section{Many-to-One Matching}

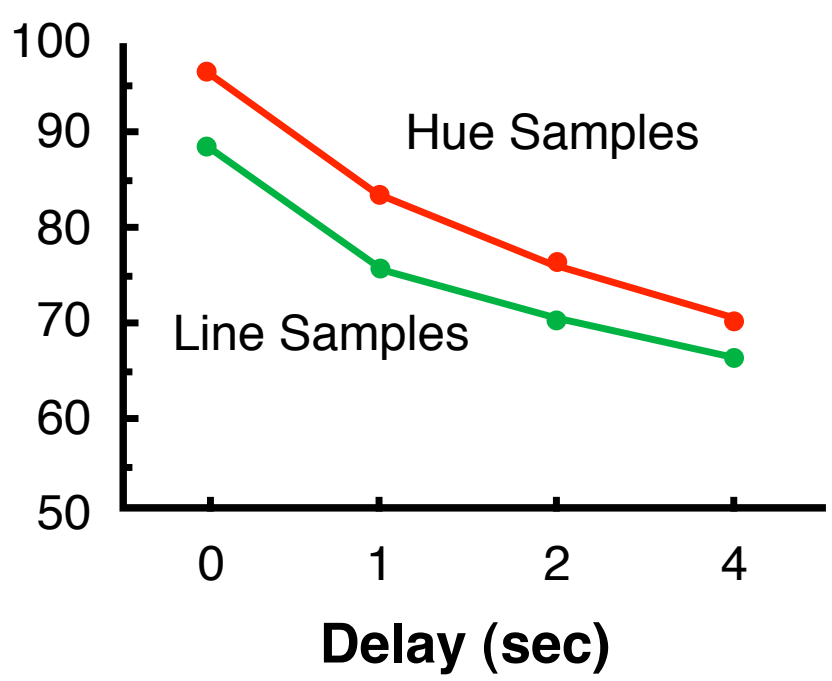

Figure 4. Retention functions following matching training in which hue samples and line-orientation samples were associated with different comparisons (one-to-one matching) or common comparisons (many-to-one matching) (adapted from Zentall, Urcuioli, Jagielo, \& Jackson-Smith, 1989).

identifying the nature of those representations in a nonverbal organism would seem to be a more challenging task than in the case of a verbal human.

If two stimuli, A and B, are each associated with a common third stimulus, $\mathrm{C}$, then one possible candidate for the common representation would be a prospective representation of Stimulus C. Thus, seeing either A or B might activate an anticipatory representation of $\mathrm{C}$. But, it is also possible that conditioned to the new correct comparison (e.g., blue). Finally, on test trials, presentation of the vertical-line sample evokes a representation of the correct comparison (circle); but, that representation is now associated with choice of the blue comparison based on interpolated training, so the vertical-sample, blue-comparison association emerges without specific training.

The prospective common-coding hypothesis receives sup- 
Table 3. A mediated generalization account of common coding effects in many-to-one matching

\begin{tabular}{lcl}
\multicolumn{2}{c}{ Training } & Testing \\
\hline Phase 1 & Phase 2 & Phase 3 \\
\hline R-"c"-C+ & R-"c"=B+ & \\
G-"d"-D+ & G-"d"=W+ & \\
V-"c"-C+ & & V-"c"=B+ \\
H-"d"-D+ & & H-"d"=W+ \\
\hline
\end{tabular}

Note. $R=$ red, $G=$ green, $V=$ vertical lines, $H=$ horizontal lines, $C=$ circle, $D=d o t$. " $c$ " and " $d$ " represent circle and dot mediating responses, respectively, to the samples $(R$, $G, V \& H)$. Dashes (-) represent associations formed during Phase 1. Double dashes (=) represent associations formed during Phase 2.

port from the finding that positive transfer has often been found following training with many-to-one matching, but positive transfer typically has not been found following training with one-to-many matching (Urcuioli, 1996). In one-to-many matching, there is one pair of samples and two pairs of comparisons, such that each sample is associated with two comparisons. As can be seen in Table 4, prospective comparison representations cannot mediate the association between the samples that were first experienced during Phase 2 interpolated training and the comparison stimuli that were experienced during Phase 1 training, but not during Phase 2 training. However, there is also growing evidence that, for pigeons, the basis of the representation on a matching trial can be a retrospective representation of one of the samples rather than a prospective representation of one of the comparison stimuli.

Perhaps the best evidence for the retrospective coding of samples during many-to-one matching comes from research in which one of the pairs of samples is defined by the presence versus absence of a stimulus (Zentall, Sherburne, \& Urcuioli, 1995). Presence versus absence samples can be a hue or a shape versus nothing, or food versus the absence of food. For example, in Zentall et al. (1995), when the sample was food, choice of the vertical-line comparison was correct; but, when the sample was the absence of food (nothing), choice of the horizontal line comparison was correct. On other trials, the samples were red or green and the correct response was to vertical and horizontal lines, respectively.

To understand the reasoning behind this experiment requires some background. When samples consist of a pair of stimuli (e.g., red and green), and one introduces a delay be-
Table 4. The ability of a mediated generalization account of common coding effects to account for the failure to find transfer of training in one-to-many matching.

\begin{tabular}{lll}
\multicolumn{2}{c}{ Training } & Testing \\
\hline Phase 1 & Phase 2 & Phase 3 \\
\hline C-"r"-R+ & B-"r"=R+ & \\
D-"g"-G+ & W-"g"=G+ & \\
C-"v"-V+ & & B-"r"= $(\mathrm{V}+)$ \\
D-"h"-H+ & & W-"g"=(H+) \\
\hline
\end{tabular}

Note. $R=$ red,$G=$ green, $V=$ vertical lines, $H=$ horizontal lines, $C=$ circle, $D=$ dot. " $r$ ", " $g$ ", "v", and " $h$ " represent $r e d$, green, vertical, and horizontal mediating responses, respectively, to the samples ( $C$ and $D)$. Dashes (-) represent associations formed during Phase 1. Double dashes (=) represent associations formed during Phase 2. Dashes (-) represent associations formed during Phase 1. Double dashes (=) represent associations formed during Phase 2. Stimuli in parentheses represent the actual comparison stimuli in Phase 3. Thus, in testing, $B$ and $W$ will elicit mediating responses " $r$ " and " $g$ " rather than " $v$ " and " $h$ " and transfer of training should not result.

tween the offset of the sample and the onset of the comparison stimuli, the retention functions for trials involving the two sample types typically appear quite similar to each other and decline gradually to 50\% correct choice (e.g., Weaver, Dorrance, \& Zentall, 1999). However, when the samples consist of the presence versus the absence of a stimulus, the retention functions for the two samples types typically diverge. Curiously, the retention function on present-sample trials declines rapidly, often to below chance levels of accuracy, whereas the retention function on absent-sample trials typically remains high and flat.

This unique pattern of results has been interpreted as evidence that pigeons have developed a single-code/default coding strategy (Colwill, 1984; Grant, 1991; Wilson \& Boakes, 1985); that is, on present-sample trials, choice of the comparison associated with the present sample occurs whenever there is a representation of that sample in memory; otherwise, choice of the alternative comparison occurs by default. Thus, on present-sample trials, as the delays increase in duration, memory of the present sample is gradually lost and there is an increasing tendency to respond to the alternative comparison, by default. On absent-sample trials, however, the sample is not encoded; thus, there is no memory loss as the delays increase in duration, and the retention function remains high. Although alternative accounts 
of this phenomenon have been proposed (see Weaver et al., 1999; Zentall, Kaiser, Clement, Weaver, \& Campbell, 2000), for the present purposes, it is not important why those retention functions diverge, only that they do, and that the more typical present-present-sample matching retention functions (e.g., matching-to-sample with red and green samples) do not diverge with increasing delays.

We can now examine the rationale for the experiment. Given the differences in retention functions for these two classes of samples, one might be able to identify the nature of the common code by combining present-absent (food/nofood) samples and present-present (red/green) samples in many-to-one matching and by examining the slopes of the resulting retention functions. If pigeons learned to represent the hues as food and its absence, then one would expect both food/no-food retention functions and red/green retention functions to diverge with increasing retention intervals. The retention functions on food-sample trials and on trials involving the hue sample associated with the same comparison as food samples should be steep and the retention functions on no-food-sample trials and on trials involving the hue sample associated with the same comparison as no-food samples should be high and flat. On the other hand, if pigeons represent the food and no-food samples as hues, then one would expect both food/no-food retention functions and $\mathrm{red} /$ green retention functions to decline at the same rate and to be superimposed.

Zentall et al. (1995) found that the retention functions on food-sample trials were steep and that those on no-food sample trials were flat (i.e., they were divergent as they tend to be when training involves those two samples alone). More important, similar divergent retention functions were found on red and green sample trials (see Figure 5). For the hue sample that was associated with the same comparison as the food sample, the retention function was steep and fell below chance with increasing retention intervals, whereas for the hue sample associated with the same comparison as the nofood sample, the retention function was high and relatively flat. These results suggest that, in the context of many-to-one matching involving food and no-food samples, the remaining red and green samples are coded as retrospective representations of food and its absence.

\subsection{Other Procedures for Creating Associative Classes}

\subsubsection{Common reinforcement history.}

A special case of the common representation of arbitrary stimuli has been reported by Vaughan (1988). In this research, the defining characteristic of each of two stimulus classes (i.e., whether responding to members of one class would be reinforced and whether responding to members of the other class would not) was allowed to vary from session to session of training, such that the value of each class over sessions was the same (members of both classes served equally often as positive, $\mathrm{S}+$, and negative, S-, stimuli). In fact, the only feature that could be used to distinguish between the classes was the reinforcement conditions that were constant within a training session, but that varied between sessions. Vaughan first randomly assigned photographs of trees to two arbitrary sets: A and B. After training pigeons that responses to stimuli in Set A were reinforced and responses to stimuli in Set B were not, the valence associated with each set was reversed, and then reversed again, repeatedly. After a large number of such reversals, Vaughan found that, early in a session (i.e., after a small number of stimuli from each set had been presented), the pigeons would respond appropriately to the remaining members of each set. Thus, these arbitrarily assigned stimuli had become two functional stimulus classes, in spite of the fact that they shared no more in common (in terms of their physical similarity or their overall reinforcement histories) than they did with members of the other class. So, once the current status of each set was determined, the pigeons would respond appropriately to the remaining members.

\subsubsection{Symmetry training.}

Having two stimuli associated with the same comparison or outcome may not be the only procedure that can produce a functional equivalence between stimuli. Zentall, Clem-

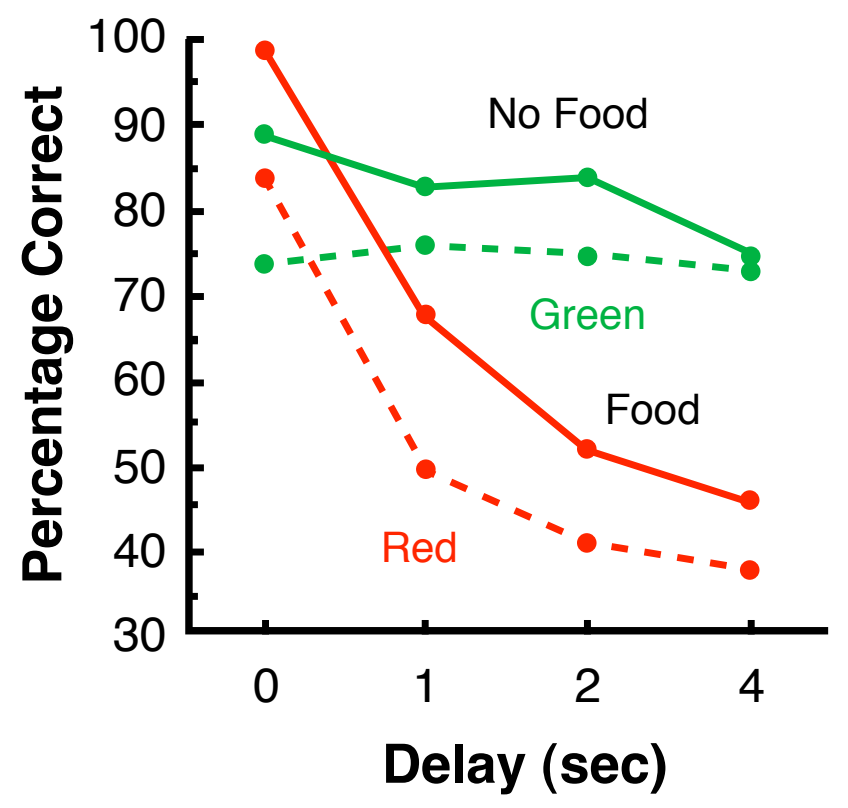

Figure 5. Retention functions following many-to-one matching training in which red and food samples were associated with choice of a vertical-line comparison and green and nofood samples were associated with choice of a horizontalline comparison (adapted from Zentall, Sherburne, \& Urcuioli, 1995). 
ent, and Weaver (2003) asked if bidirectional training (A$\mathrm{B}$ and $\mathrm{B}-\mathrm{A}$ ) can encourage pigeons to treat two stimuli as functionally equivalent. The rationale for this procedure was the recognition that the directionality of an association may play an important part in the nature of the association. Certainly, this is true of Pavlovian associations; forward associative training (CS-US) results in a strong conditioned response, whereas backward associative training (US-CS) does not. Furthermore, if following matching training, one interchanges the samples with the comparisons, then little evidence of transfer has been generally been found (Gray, 1966; Hogan \& Zentall, 1977; Richards, 1988; Rodewald, 1974; but, see Frank \& Wasserman, 2005, for more much encouraging results). However, training the association in both directions might eliminate the directionality of an association. Such training may encourage animals to consider the two stimuli involved in this training as having similar meaning.

In symmetry training, subjects learn that when Stimulus A appears first, it is always followed by Stimulus B and when Stimulus B appears first, it is always followed by Stimulus A. If this procedure effectively establishes the functional equivalence of $\mathrm{A}$ and $\mathrm{B}$, then one should be able to train a new association between one of those stimuli (e.g., A) with new Stimulus $C$ and then show that an emergent relation has developed between the remaining stimulus (i.e., B) and new Stimulus C. Zentall et al. (2003) found that such training can in fact result in transfer to a new association when one of those symmetry-trained stimuli is associated with a new stimulus in a matching task and the remaining symmetrytrained stimulus replaces the first (see also, Yamamoto \& Asano, 1995).

\subsubsection{Formal stimulus equivalence}

An extensive program of research on formal stimulus equivalence began with a now classic experiment by Sidman (1971). Sidman trained a severely retarded child with limited verbal ability to select the appropriate picture of an object when the word for the object was spoken (A-B). The child was also trained to select the written word for an object when the word for the object was spoken (A-C). Sidman found that the child could then select the appropriate picture of an object when presented with the written word for that object (C-B).

Sidman and Tailby (1982) formalized the stimulus equivalence paradigm. They proposed that formal equivalence required that one demonstrate three fundamental stimulus relations. (1) Reflexivity (or generalized identity matching): If trained to select Comparison A after being presented with Sample A, then one would select Comparison B after being presented with Sample B. (2) Symmetry (or bidirectional- ity): If trained to select Comparison B after being presented with Sample A, then one would select Comparison A after being presented with Sample B. (3) Transitivity (or mediated learning): If trained to select Comparison B after being presented with Sample A and trained to select Comparison C after being presented with Sample B, one would then select Comparison $\mathrm{C}$ after being presented with Sample A.

Sidman and Tailby (1982) reasoned that if one could show generalized identity matching, then symmetry and transitivity could be demonstrated by training A-B as well as A-C and finding an emergent B-C (or C-B) relation. Later, Sidman (1990) argued that one could show all three properties of formal equivalence by training A-B as well as B-C and demonstrating the emergence of an untrained $C_{-}$A relation. The reasoning was that an emergent A-C relation would demonstrate transitivity, but an emergent $\mathrm{C}$-A relation would also demonstrate symmetry, and because it implies A-A, reflexivity as well. Such evidence for formal stimulus equivalence has often been found in humans (see Adams, Fields, \& Verhave, 1993). It has also been found in California sea lions (Schusterman \& Kastak, 1993) and in chimpanzees (Yamamoto \& Asano, 1995), but it appears to be difficult to demonstrate in other nonhuman animals such as pigeons.

Zentall (1996) proposed that this difficulty is attributable to the directionality imposed by the nature of the conditional discrimination for animals. Specifically, although symmetry training appears to be sufficient to establish functional equivalence, it is difficult to demonstrate an emergent symmetry relation in animals because, in training, the association between sample and correct comparison choice is followed by reinforcement; logically, this is a unidirectional association (but see Frank \& Wasserman, 2005).

\subsubsection{Learning by exclusion}

The emergence of untrained relations between unrelated stimuli can also be demonstrated when an animal learns by exclusion (Kastak \& Schusterman, 2002). Learning by exclusion (also called fast mapping; Carey, 1978) involves training an animal on a conditional discrimination (e.g., Sample 1 requires a response to Comparison 1, S1-C1, and Sample 2 requires a response to Comparison 2, S2-C2) and then introducing a novel sample, $\mathrm{S} 3$ with a choice between a novel comparison, $\mathrm{C} 3$, and a familiar comparison, say, $\mathrm{C} 1$. Choice of $\mathrm{C} 3$ implies that the animal has excluded $\mathrm{C} 1$ because of its prior association with S1. It may be, however, that given a choice between a familiar comparison and a novel comparison, the animal merely has a tendency to select the novel comparison. However, Clement and Zentall (2003) have shown that pigeons will choose by exclusion even when neither comparison is novel.

But, it is possible that animals can choose by exclusion 
yet not learn those specific associations as the result of that experience. Evidence for learning by exclusion requires a more stringent test. Specifically, an animal may choose C3 over $\mathrm{C} 1$ when presented with $\mathrm{S} 3$ and it may also choose $\mathrm{C} 4$ over $\mathrm{C} 2$ when presented with $\mathrm{S} 4$, but learning by exclusion requires that, when later presented with $\mathrm{S} 3$ and a choice between C3 and C4, the animal chooses C3. Kastak and Schusterman have shown just such learning in California sea lions and more recently Kaminski, Call, and Fischer (2004) have found evidence for learning by exclusion in a domestic dog.

\subsubsection{Functional Classes}

A functional class is a kind of associative class in which the common association is presumably an acquired function possessed by all of the members of the class (Savage-Rumbaugh, Rumbaugh, Smith, \& Lawson, 1980). In the study by Savage-Rumbaugh and her colleagues, chimpanzees were first trained to label a set of objects (bean-cake, orange, and bread) as 'food' (edible) and a different set of objects (stick, key, and money) as 'tools' (inedible). When presented with other objects that were untrained members of the two classes, two of the three chimpanzees labeled the new items correctly. Although it is possible that perceptual aspects of the two sets of objects aided in their categorization (see section on perceptual classes), it is also possible that functional aspects of the objects were used to classify them (i.e., as edible and inedible; see also Bovet \& Vauclair, 1998, 2001). Functional classes may also be related to relational classes in the sense that a relationship among the trained objects in a class must be extracted to be able to correctly label the novel objects.

\subsection{Summary}

The experiments described in this section suggest that many-to-one matching training results in the development of emergent relations between samples associated with a common comparison that can be described as functional equivalences. Perhaps the most convincing evidence of these functional equivalences comes from the results of transfer of training procedures in which, following many-to-one matching training and the reassignment of one pair of the original samples to new comparisons, emergent relations can be shown to have developed between the remaining samples and the new comparison stimuli. Further research has indicated that the nature of the functional equivalence is likely to be the common representation of the two samples that were associated with the same comparison.

There is also evidence that functional equivalences are not unique to the many-to-one matching procedure. Functional equivalences have been found following symmetry training and following Vaughan's (1988) multiple-reversal procedure. Thus, the development of associative classes is a robust and general phenomenon in the nonhuman animal literature. Furthermore, associative classes comprising large numbers of exemplars have been found with this procedure.

Formal equivalence - a special case of emergent stimulus relations involving reflexivity, symmetry, and transitivity - appears to be difficult to demonstrate in pigeons, but this failure may result from the strong directionality of stimulus relations produced by the specific procedures used rather than by a conceptual deficit in the animals. Similarly, learning by exclusion - a conceptual ability that can be found relatively easily in humans (see Dixon, 1977) - thus far also appears to be somewhat limited in nonhuman animals. Finally, the learning of functional classes, which allows novel objects to be sorted according to their function rather than their perceptual features, has so far only been documented in baboons and apes. Although humans have perfected the application of associative concepts in their use of language to refer to objects not currently present, the capacity to show emergent (untrained) associations, an all important property of human language, appears to be present in nonhuman animals as well.

\section{Relational Classes}

Relational classes, like associative classes, do not depend on the absolute perceptual properties of stimuli. In fact, individual stimuli cannot be assigned to a relational class because such classes depend on the relationship among stimuli; they thus require stimulus comparison. Examples of relational classes are: larger than, brighter than, heavier than, and better (or more reinforcing) than. Thus, a single stimulus can belong to one class (better than) if the stimulus to which it is being compared is worse, while that same stimulus can belong to another class (worse than) if the stimulus to which it is being compared is better.

A potential problem in interpreting the results of experiments examining the formation of relational classes is that relational responding to stimuli lying along a continuum (e.g., better than or larger than) may be explained in terms of the generalization of absolute associative values of those stimuli. According to Spence (1937), when one trains a simple discrimination involving two values along one of these dimensions, the absolute stimulus generalization gradients that form around the training stimuli should sum algebraically to produce a net stimulus generalization gradient that has its peak at a value that is displaced from the $\mathrm{S}+$ in the direction away from the S-. For this reason, any test involving stimuli that are not too far removed from the $\mathrm{S}+$ or the S- may produce what can be interpreted as relational responding, so-called transposition. This associative account is problematic for the development of a relational class, because the generalization of absolute values may pro- 
vide a more parsimonious interpretation of such responding than a relational interpretation (see Lazareva, Wasserman, \& Young, 2005 for a critical discussion of these issues and new data which challenge Spence's classical account).

\subsection{Transitive Inference}

One way to contend with the problem of differential absolute value is to use stimuli that can be described in purely relational terms, as is the case with the transitive inference effect. In its simplest form, transitive inference can be described as the presentation of two propositions (e.g., A is better than B and B is better than C) from which an inference can be made (i.e., A is better than C). Transitive responding provides evidence for the development of emergent relations among stimuli and has been used to assess the age at which children are able to reason (Piaget, 1928).

Bryant and Trabasso (1971) helped to refine the transitive inference procedure by expanding the task to five terms (to avoid end-point effects as in the above example, where A is always better and $\mathrm{C}$ is never better). More importantly, Bryant and Trabasso developed a nonverbal version of the task, in which four discriminations are trained $(\mathrm{A}+\mathrm{B}-, \mathrm{B}+\mathrm{C}-$, $\mathrm{C}+\mathrm{D}-, \mathrm{D}+\mathrm{E}-)$ and transitive responding is demonstrated on $\mathrm{BD}$ test trials when $\mathrm{B}$ is selected over $\mathrm{D}$.

More recently, this version of the task has been used to document transitive responding in several different species including rats (Davis, 1992; Roberts \& Phelps, 1994), pigeons (Fersen, Wynne, Delius, \& Staddon, 1991; Steirn, Weaver, \& Zentall, 1995; Lazareva \& Wasserman, 2006), crows (Lazareva, Smirnova, Bagozkaja, Zorina, Rayevsky, \& Wasserman, 2004), monkeys (McGonigle \& Chalmers, 1977), and chimpanzees (Boysen, Berntson, Shreyer, \& Quigley, 1993; Gillan, 1981).

Although some authors have proposed that transitive responding can be explained by simpler conditioning processes, such as the specific reinforcement histories associated with the test stimuli (Couvillon \& Bitterman, 1992; Wynne, 1997; Siemann \& Delius, 1998) or to differential value transfer from the positive stimuli with which the test stimuli were paired during training (Fersen et al., 1991), recent evidence suggests that such emergent responding can be found even when these simpler processes are largely ruled out (Roberts \& Phelps, 1994; Weaver, Steirn, \& Zentall, 1997; Lazareva et al., 2004; Lazareva \& Wasserman, 2006).

There has been some speculation that transitive inference allows animals to learn their place in dominance hierarchies without the risks involved in learning their dominance status relative to every member of the group. Instead, an animal can learn its dominance status relative to a few animals whose rank is similar to its own and then, through observa- tion, learn the dominance rank of the other animals, relative to those animals whose rank is already known. Recent research suggests that such dominance hierarchies can be acquired through observation by pinyon jays (Pas-y-Miño, Bond, Kamil, \& Balda, 2004), hens (Hogue, Beaugrand, \& Lague, 1996) and even fish (Grosenik, Clement, \& Fernal, 2007). Although transitive inference may aid in the acquisition of dominance hierarchies, it seems unlikely that the efficient development of dominance hierarchies is responsible for the arbitrary form of transitive inference that has been found in nonsocial tasks.

\subsection{Same/Different Learning}

Another kind of relational class that does not suffer from an absolute learning account is same/different. A pair of stimuli is judged to be the same if they are identical and judged to be different if they are nonidentical, without regard to the properties of the individual stimuli. Of course, merely training animals to sort pairs of stimuli according to whether they do or do not appear to be the same is not sufficient evidence that the animals have the capacity to make same/different judgments, because the animals may simply have learned to sort the particular training stimuli according to their absolute properties. What is needed is evidence that the identity relation controls comparison choice; this evidence comes from generalization tests with novel stimuli.

In an early study of same/different discrimination learning, Zentall and Hogan (1976) found that, if pigeons were trained to choose the same shape as the sample, they then showed better transfer of that training to new stimuli which differed in color than did pigeons that were originally trained to choose a shape which was different from the sample. Unfortunately, pigeons tend to be neophobic and the presentation of novel stimuli appears to interfere with immediate transfer of matching.

To overcome this problem, Zentall, Edwards, Moore, and Hogan (1981) used an alternative strategy; their procedure involved training on matching-to-sample and oddity-fromsample with four different hues as samples. Each sample hue was experienced with two of the three remaining hues as the nonmatching comparison. On test trials, the remaining hue replaced either the matching or the nonmatching comparison and choice accuracy was assessed. For pigeons trained on matching, the results were straightforward. Replacing the correct (or matching) comparison resulted in a large decrease in choice accuracy, whereas replacing the incorrect (or nonmatching) comparison resulted in no decrease in choice accuracy. But, for pigeons trained on oddity, the results were surprising. Replacing the correct (or nonmatching) comparison resulted in little decrease in choice accuracy, whereas replacing the incorrect (or matching) comparison led to a 
large decrease in choice accuracy (see Figure 6). Thus, in spite of the fact that these pigeons had both the sample and the correct comparison present, the absence of the incorrect (matching) comparison prevented good transfer. On the other hand, the presence of the incorrect (matching) comparison was sufficient to promote good transfer. For both groups, acquisition appeared to be based on the presence of the comparison that matched the sample; but, once it was identified, pigeons in the matching condition chose it, whereas pigeons in the oddity condition chose the alternative comparison.

In recent years, studies of both birds and mammals have revealed even better evidence for the transfer of conceptual same/different discriminations (e.g., Blaisdell \& Cook, 2005; Katz, Wright, \& Bachevalier, 2002; Mercado, Killebrew, Pack, Macha, \& Herman, 2000; Oden, Thompson \& Premack, 1988; Pepperberg, 1987; Wright, Cook, Rivera, Sands, \& Delius, 1988; see Wasserman, Young, \& Cook, 2004 and Wright \& Katz, 2006 for reviews). These more recent experiments have shown that experience with several examples of same/different relations increases the tendency of pigeons and both old- and new-world monkeys to transfer that training to new stimuli (Katz, Wright, \& Bachevalier, 2002; Wright et al., 1988; Wright, Rivera, Katz \& Bach-

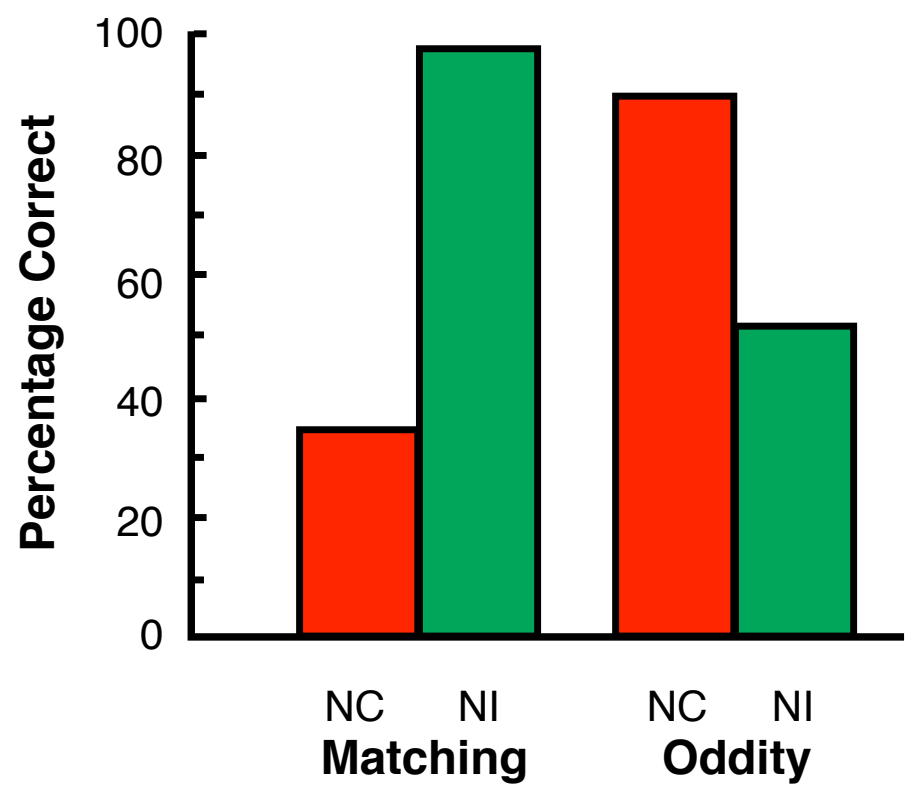

Figure 6. Evidence of the role of generalized identity learning in matching-to-sample and oddity-from-sample training. When the identity relation is removed by replacing the correct comparison (New Correct - NC) for matching or the incorrect comparison (new incorrect - NI) for oddity accuracy is quite poor. But when the identity relation remains for matching (new incorrect - NI) or oddity (new correct - NC) accuracy remains quite high (adapted from Zentall, Edwards, Moore, \& Hogan, 1981). evalier, 2003). However, no such constraint or limitation of stimulus set size seems to hold for chimpanzees (Oden, Thompson, \& Premack, 1988).

\subsubsection{Same/Different learning using multiple-item dis- plays: Effect of entropy}

Investigations of pigeons and baboons by Wasserman, Young, Fagot and their colleagues have used as discriminative stimuli arrays of black-and-white computer icons that were either all the same as or all different from one another (see Figure 7 for arrays). In one example (Wasserman et al., 1995; Young \& Wasserman, 1997, Experiment 1), pigeons were first taught to peck one button when they viewed an array that comprised 16 copies of the same icon and to peck a second button when they viewed an array that comprised one copy of 16 different icons (a same-different discrimination task). These same and different training displays were created from one set of 16 computer icons. The pigeons were later tested with new same and new different displays that were created from a second set of 16 computer icons that had never before been shown during discrimination training. Accuracy to the training stimuli averaged from $83 \%$ to 93\% correct and accuracy to the testing stimuli averaged from $71 \%$ to $79 \%$ correct; in each case, choice accuracy reliably exceeded the chance score of $50 \%$ correct. Such robust discrimination learning and stimulus generalization attest to the pigeon's acquisition of an abstract same-different concept (for more on the nature of this concept, see Wasserman, Young, \& Nolan, 2000; Young \& Wasserman, 1997; Young, Wasserman, \& Dalrymple, 1997; Young, et al., 1997). Should these results be taken at face value? Perhaps not.

The authors decided to see what effect, if any, the number of icons had on the pigeon's same-different discrimination. They began training the pigeons that had successfully learned and transferred the 16-icon same-different discrimination with displays of $12,8,4$, and 2 icons. The result was unexpected failure. The pigeons stopped pecking after only 1 or 2 days of training. This cessation of responding was not random; the birds stopped responding on 2-icon different trials. Prior to this stoppage, the pigeons repeatedly pecked the "same" report key despite the presentation of 2 different icons. The authors pondered this result for some time; but, they could make no sense of it. So, they decided to change direction and to see how pigeons would respond to displays that comprised a mixture of same and different icons. This issue was of interest in its own right, but the authors had no idea that the results of such same/different mixtures would help them understand the pigeon's peculiar performance with small numbers of icons.

The same arrays and the different arrays in these experiments really represent the endpoints of a scale of variabil- 
ity. The same displays entail minimal variability, with all 16 icons the same as one another, whereas the different displays entail maximal variability, with all 16 icons different from one another. So, the authors explored pigeons' response to intermediate degrees of variability (Young \& Wasserman, 1997, Experiment 2). They constructed three mixture arrays: 2 icons each repeated 8 times ( 2 icons x 8 copies), 4 icons each repeated 4 times ( 4 icons $x 4$ copies), and 8 icons each repeated twice ( 8 icons $\times 2$ copies). These mixtures were presented as rare probe tests and food reinforcement was given after all of the pigeons' report responses. It was not obvious how the pigeons would respond to these mixture displays. All three mixtures included more than one kind of icon, perhaps prompting the pigeons to make a "different" response; but, all three mixtures also included repetitions of icons, which might prompt the pigeons to make a "same" response. It was also possible that the pigeons would show a graded change in responding as the displays went from being all same ( 1 icon $x 16$ copies) to all different (16 icons $x$ 1 copy), thus disclosing a sensitivity to differing degrees of display variability. In fact, the pigeons exhibited a smooth transition in their responding as the mixture arrays changed from 16 icons $x 1$ copy (different) to 8 icons $x 2$ copies to 4 icons $\mathrm{x} 4$ copies to 2 icons $\times 8$ copies to 1 icon $\times 16$ copies (same), suggesting some form of dimensional stimulus control.

Over a half century ago, Shannon and Weaver (1949) quantified the amount of variety or diversity in a categorical variable by a weighted average of the number of bits of information that are required to predict each of the categories of the variable. That score - entropy - nicely fit the pigeons' response to same/different mixtures (Young \& Wasserman, 1997). It also suggested a way to understand why the number of items had such a strong effect on pigeons' behavior.

To first gain more quantitative information about the effect of the number of items on discrimination behavior, Young, Wasserman, and Garner (1997, Experiment 1) trained pigeons on 16-item displays and later tested the pigeons with displays containing fewer items. Birds were given nondifferentially reinforced testing displays comprising $2,4,8,12$, or 14 items that were either the same as or different from one another. The use of nondifferential reinforcement meant that the extinction of responding that was earlier observed under differential reinforcement would not now affect testing performance. Discrimination of 16-icon same from different training arrays averaged $89 \%$ correct. Discrimination of same from different 2-, 4-, 8-, 12-, and 14-icon testing arrays averaged $49 \%, 54 \%, 73 \%, 79 \%$, and $83 \%$ correct, respectively. More detailed examination of choice behavior disclosed that the decline in performance with smaller arrays was due to an increase in errors to the different arrays. The probability of choosing "different" did not vary across the six same trial array sizes, but it did vary across the six different trial array sizes; the fewer the icons, the lower the probability of choosing "different." In fact, the pigeons strongly reported "same" to the 2- and 4-icon different displays. Why?

When pigeons are trained to discriminate 16-icon same arrays from 16-icon different arrays, they may actually have learned to make one response to displays with an entropy of 0.0 and another response to displays with an entropy of 4.0. During testing, a bird might distribute its responses to novel arrays as a function of their entropy; displays with entropies closer to 0.0 should be classified as "same," whereas those with entropies closer to 4.0 should be classified as "different." The entropy of a 2-item different display, 1.0, is more similar to that of 16 -item same displays, 0.0 , than it is to that of 16-item different displays, 4.0. Thus, this entropy discrimination should prompt classification of 2-item different displays as "same" rather than as "different," in accord with earlier findings. These results thus represent an important and counterintuitive confirmation of pigeons' use of entropy in classifying complex visual displays.

The next step was to learn more about the comparative generality of these pigeon results. So, the authors explored the extent to which a nonhuman primate's same-different discrimination behavior resembled that of pigeons. They were not only interested in whether primates can learn a same-different concept (prior evidence suggests that they can, e.g., Wright et al., 1983), but they were also interested in whether the nature of that concept learning is categorical or dimensional. Wasserman, Fagot, and Young (2001) thus trained and tested baboons with the same experimental stimuli as previously used with pigeons. Experiment 1 found close correspondence between baboons and pigeons in their discriminative responding to familiar and novel arrays of same and different items: (a) baboons quickly learned to discriminate same from different stimulus arrays that comprised 16 icons and (b) baboons effectively generalized that same-different discrimination to arrays of novel icons. Accuracy to the training stimuli averaged $91 \%$ correct and accuracy to the testing stimuli averaged $81 \%$ correct; in each case, choice accuracy reliably exceeded the chance score of $50 \%$ correct. Experiments 2 and 3 showed close correspondence between baboons' and pigeons' responses to mixed arrays that comprised both same and different icons: the baboons exhibited graded responding that accorded with display variability. The authors (Wasserman, Young, \& Fagot, 2001) later varied the number of icons in the arrays to see if baboons' behavior would be affected by this manipulation. Decreasing the number of icons from the training value of 16 had a large decremental impact on baboon's discrimination of same from different displays, as had been true of pigeons (Young et al., 1997). 


\subsubsection{Same/Different learning using multiple-item dis- plays in humans}

The fact that such widely different species as pigeons and baboons responded so similarly to familiar and to novel same and different displays as well as the fact that these two species responded so similarly to mixed displays of same and different items and to reductions in the number of displayed items strongly suggests that these results may have broad applicability to other animals given similar discrimination training and generalization testing tasks. Yet, these results with pigeons and baboons struck the authors as most peculiar from the vantage point of human judgment. Surely, humans would not respond as had pigeons and baboons. If humans were given mixtures of same and different icons, then one would certainly expect them to respond "different" so long as any of the items differed from one another. And, varying the number of icons should certainly have no measurable effect on performance; after all, two different items are just as different from one another as are eight different items. With no available data on the question, the authors conducted a project with college students to parallel the research that they had completed with pigeons and baboons.

Young and Wasserman (2001, Experiment 1) first taught college students to discriminate same from different arrays. Students were told that they would be viewing a series of arrays and attempting to learn which response was correct for each. Students were to make their best guess as to which of two responses was correct; they were then given feedback in the form of a tone (correct) or a flash of the screen (incorrect). For half of the participants, the "1" key of a computer keyboard was correct for same arrays and the " 3 " key was correct for different arrays. For the other half of the participants, the keys assignments were reversed. The goal of the student participants was to predict the correct response for each array. The words "same" or "different" were never used in the instructions. The authors then tested the students with displays of intermediate variability and with displays comprising fewer icons.

Students' responding to the testing arrays that contained fewer than 16 icons or that were mixtures of same and different icons revealed disparate behavioral profiles. To separate the disparate profiles, the authors performed a hierarchical cluster analysis of responding to the different arrays and focused on the highest-level two-cluster division: $80 \%$ of the students were in one cluster and $20 \%$ were in the other. The authors used only the different arrays in their cluster analysis to determine whether disparities in responding to those arrays would predict disparities in responding to the mixture arrays. Students in the smaller (Continuous) cluster responded in accord with the use of entropy; they were more likely to choose "same" to the different arrays as the number of icons was reduced, but they consistently chose "same" to the same arrays regardless of icon number. The Continuous students also exhibited a strong sensitivity to the full range of display variability to the mixture arrays; as the mixture was changed from mostly same to mostly different icons, responding changed from mostly "same" to mostly "different." So, people in the Continuous cluster responded as if display variability were measured along a continuous scale, just like pigeons and baboons. Students in the larger (Categorical) cluster behaved quite differently, treating the discrimination more categorically; they were largely unaffected by the number of icons in the same and different displays. Plus, these students nearly always made a "different" response to all of the mixtures (although there was a modest effect of the composition of the mixtures); when any of the icons were different, they tended to choose "different;" only when all of the icons were identical did they consistently choose "same." None of the individual difference characteristics that were examined (handedness, American College Test scores, sex, grade point average, or age) accounted for the disparate behavioral profiles among the students.

These data suggest that the continuous response profile is not unique to nonhuman animals; some humans also exhibit this pattern. But, most humans and, so far, no nonhumans have exhibited the categorical response profile. Perhaps only language-experienced apes and humans will respond with the categorical profile. The fact that some humans exhibit the continuous response profile may indicate that these individuals do not deploy language in performing the same-different discrimination.

How might language participate in these two disparate patterns of same-different discrimination performance? One possibility is that having specific symbols for "same" and "different" may effectively transform a discrimination that is mediated by variability or entropy into one that is leveraged by linguistic categorical labeling (for discussions of labeling effects on conceptual classification by nonhuman animals, see, for example: de Rose, 1996; Horne \& Lowe, 1996; Stromer \& MacKay, 1996). Another possibility is that this dramatic disparity between the dichotomization and the dimensionalization of same and different stimulus arrays is more apparent than real. All organisms may scale the stimuli in terms of entropy, but their same-different decisions may arise from setting different thresholds. Subjects that appear to be dichotomizing the stimuli may place their decision threshold near an entropy value of 0.0 , whereas subjects that appear to be dimensionalizing the stimuli may place their decision threshold near the midpoint of the entropy range.

\subsection{Summary}

Evidence for the development of relational concepts 
comes from transitive inference performance and same/different learning. Although the mechanism responsible for transitive inference performance is not well understood, evidence from several studies suggests that it cannot be attributed to simpler conditioning processes such as the specific reinforcement histories associated with the test stimuli or to differential value transfer from the positive stimuli with which the test stimuli were paired during training.

In the case of same/different discrimination learning involving a single sample stimulus and a choice of two comparison stimuli, transfer to novel stimuli has been spontaneous in the case of chimpanzees, and, in the case of monkeys and pigeons, is typically facilitated by large training stimulus set sizes. There is also evidence that the novelty of the transfer stimuli may obscure better transfer effects in pigeons. When same/different discrimination learning has been studied with multiple-item displays in pigeons and baboons, good evidence of transfer has been found. Later results suggest that the entropy of the display may play an important role in such discrimination learning and transfer. This hypothesis is supported by the finding that pigeons and monkeys responded to displays containing some same and some different items proportionally, rather than all or none. In contrast, most (but not all) humans responded to the intermediate displays as "different." These humans may be using linguistic categorical labeling rather than entropy as the basis of their discrimination, although it is also possible that they have merely set their threshold for responding "same" at a point different from that of pigeons and monkeys.

\section{Relations Between Relations}

The research discussed thus far provides convincing evidence that nonhuman animals can discriminate objects and events on the basis of their shared perceptual, associative, and relational properties. But, can the pigeon or any other nonhuman animal acquire a higher-order relational concept like an analogy?

For some theorists, the production and comprehension of analogies are hallmarks of human reasoning that hinge on sophisticated linguistic or representational competence (e.g., French, 1995; Gentner, 1998; Gentner, Holyoak, \& Kokinov, 2001; Holyoak, 1984; Holyoak \& Thagard, 1997; Sternberg, 1977). If so, then one might well despair of interrogating a prelinguistic human or a nonlinguistic animal about analogy. Nevertheless, as described below, comparative and developmental psychologists may now have several available means to query their respective nonlinguistic and prelinguistic subjects for evidence of their capacity to implicitly recognize and then explicitly judge, complete, and/or construct analogies.

\subsection{Analogical or Relational Matching-to-Sample}

In the analogical or relational matching-to-sample task, the animal is required to match a sample set (either two or more identical items on some trials and two or more nonidentical items on other trials) to a different distinctive set of identical or nonidentical items. Successful matching implies that the animal judges that the relation (identity or nonidentity) instantiated by one of the choice sets is the same relation as the relation (identity or nonidentity) instantiated by the sample set. This task is essentially a nonlinguistic analogy problem in which all of the arguments are visually provided. Critically, success on the analogical matching task requires the animal to attend to the higher-order relations (same or different) between relations (identity or nonidentity) because none of the items in the sample set is presented in either of the two choice sets.

When each same or each different stimulus display consists of a single pair of items, the results point to what David Premack labeled a 'profound disparity' between the analogical capacities of humans and apes on the one hand, and other animals on the other (Premack, 1978, 1983; Thompson \& Oden, 1996). Specifically (see Sections 4.3 and 4.4), no nonhuman animal other than chimpanzees with a history of symbol training has provided unequivocal evidence of its ability to categorically match a pair of sample items (e.g., a pair of padlocks) with another distinctive pair of identical objects (e.g., a pair of cups) and to match a pair of nonidentical objects (e.g., a pencil and eraser) with another pair of nonidentical objects (e.g., a shoe and ball).

\subsection{Relational Matching by Pigeons and Baboons}

Interestingly, the 'profound disparity' does not appear to hold for either pigeons or baboons when each sample and comparison 'same/different' stimulus display in the relational matching task consists of a large number of stimuli (e.g., 16) (Cook \& Wasserman, in press; Fagot, Wasserman, $\&$ Young, 2001).

Consider the task that is schematized in Figure 7. Here, an animal is shown a sample display that depicts items that are either all the same as one another or all different from one another. After presentation of the sample display, two choice displays are shown: the first of all same items and the second of all different items. The correct response is to select the choice display that involves the same relation among the items as was illustrated in the sample display. Critically, none of the icons that were shown in the sample display are shown in either of the choice displays. So, only the relations among the items in the sample and choice displays can guide discriminative responding; the particular items themselves are of no importance.

Cook and Wasserman (in press) gave this same-different relational matching task to pigeons to see if they could 
Same Sample Trial

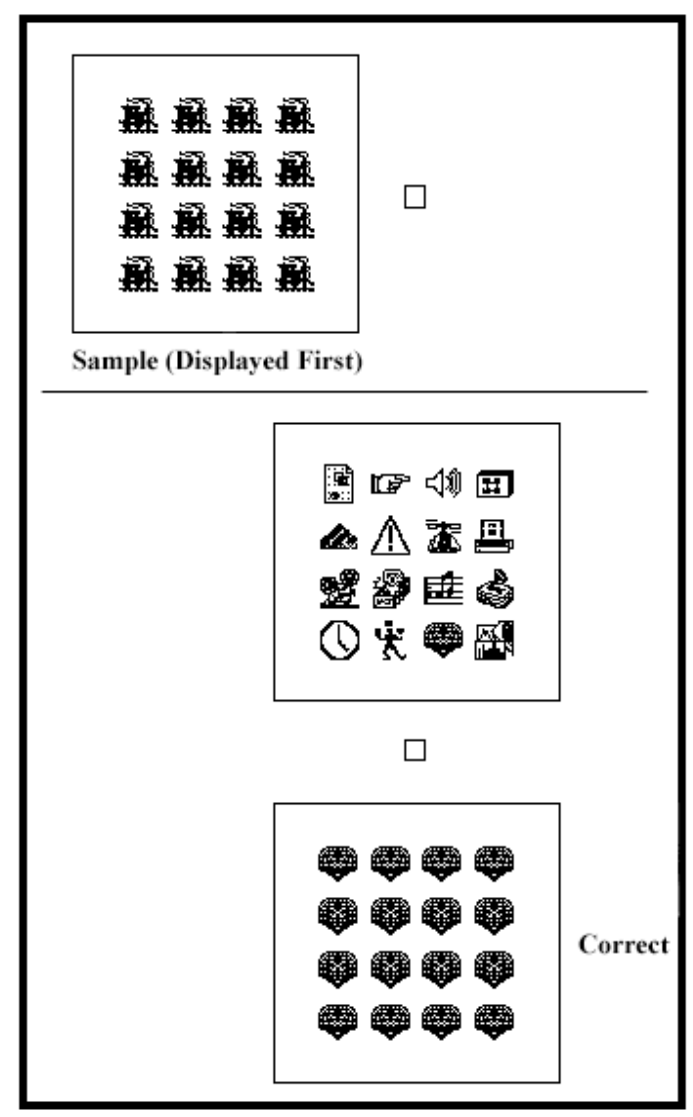

Different Sample Trial

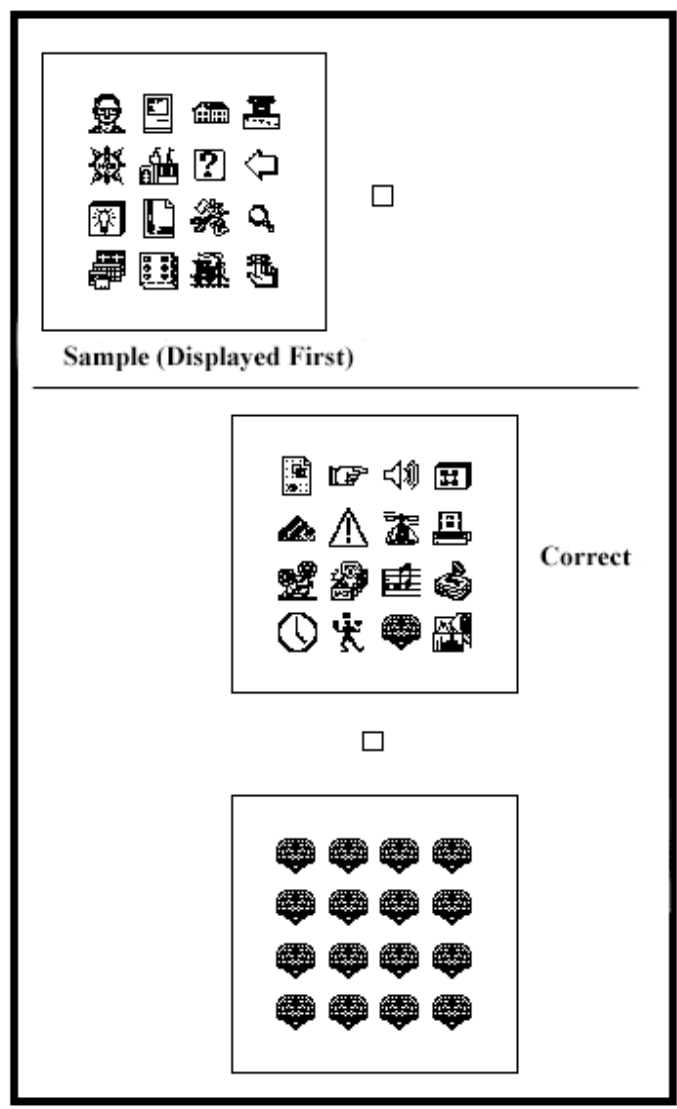

Figure 7. Exemplary Same and Different sample trials in baboons'(Papio papio) relational matching to sample training. Note that the sample items come from one set of icons and the test items come from another set of icons. (Adapted from Fagot, Wasserman \& Young, 2001).

successfully solve the task and generalize their matchingto-sample behavior to sample displays that contained novel visual icons. Successful generalization to novel sample displays would provide clear evidence that these birds had indeed learned a highly abstract and broadly applicable concept. Cook and Wasserman (in press) found just such successful discrimination learning based on the relation between relations with $4 \times 4$ grids of 16 same and different stimulus arrays drawn from five distinctive sets of colored icons. Successful transfer performance in conditions where the alignment, orientation, and size of the icons were varied and mixed provided further evidence that the birds' choices were based on their perception of abstract higher-order relations.

The effect of the number of icons in the stimulus arrays on the birds' performance was not tested in the Cook and Wasserman (in press) study, but given the results from previous studies by Wasserman and his colleagues with both pigeons and baboons, it seems reasonable to believe that stimulus variability or entropy played a critical part in the pigeons' discrimination behavior (cf., Wasserman, Fagot, \& Young, 2001; Young \& Wasserman, 1997; Young, Wasserman, \& Garner, 1997).

Indeed, in an earlier study, Fagot, Wasserman, and Young (2001) gave the same-different relational matching task with multiple icon arrays to baboons. The researchers reported that their baboons - like the pigeons in Cook and Wasserman's (in press) subsequent study - successfully matched 16-item arrays of identical icons or nonidentical icons with the corresponding comparison array instantiating the same relation. Their work then proceeded to more deeply explore the cognitive basis of this relational matching behavior.

Follow-up research investigated: (a) the effects of the number of items in a sample (and a test) display and (b) the effects of mixtures of same and different items in a sample display on relational matching-to-sample behavior. That research suggested that the baboons were strongly controlled by the variability of the items that were shown in the sample stimulus displays. 
Because their methods were then novel, for comparative purposes, Fagot et al. (2001) trained and tested humans on the same discrimination. This comparison disclosed both commonalities and disparities in the cognitive processes of abstract conceptual behavior. Baboons and humans both learned relational matching-to-sample. However, humans learned far faster than baboons and their final level of discriminative performance was much higher. Baboons and humans both transferred relational matching-to-sample to novel sample stimuli. But, only baboons showed a generalization decrement to the novel testing samples; humans responded with equivalent accuracy to the training and testing samples. Baboons and humans both showed a worsening of relational matching-to-sample performance when the number of sample icons was reduced from 16 to 12 to 8 to 4 to 2 . But, only baboons exhibited a strong tendency to report "same" to different sample displays that contained 2 or 4 icons; humans' discrimination was much more mildly and symmetrically affected by reductions in the number of sample icons. Baboons and humans both were strongly controlled by the entropy of sample displays that contained various mixtures of same icons and different icons. But, humans more abruptly and completely reported "different" to mixture sample arrays with an entropy value of 1.0 or more.

The results from the relational matching studies with pigeons and baboons unequivocally show that these animals can ignore surface similarities and match the sample and testing arrays according to the abstract relations between them. As was also true in earlier research (e.g., Wasserman et al., 2001; Young \& Wasserman 2001), neither baboons nor pigeons exhibited the strong categorical behavior that was evidenced by humans trained and tested under comparable circumstances. Nevertheless, it is clear that variability or entropy provides sufficient information for nonhuman animals (and perhaps humans as well) to make both first-order and second-order relational discriminations.

\subsection{Categorical Relational Matching by Nonhuman Pri- mates and Children}

In contrast to baboons and pigeons, Sarah, a chimpanzee (Pan troglodytes) proved to be adept at categorical analogical matching-to-sample when only two items were shown in the sample and testing alternatives (see Section 4.4 for more details). Premack $(1978,1983)$ suspected that prior "language-training" provided Sarah with the necessary cognitive scaffolding to judge the equivalence of analogical relations. Results from studies of physical and conceptual/analogical matching tasks by chimpanzees, either with or without prior experience using representational symbols for the relations of same and different, support this hypothesis.

Would other chimpanzees fare as well as Sarah? Spon- taneous analogical matching of relations between relations by chimpanzees, under conditions of nondifferential reinforcement, was reported by Thompson, Oden, and Boysen (1997). One of the animals in the study was Sarah, whose analogical capacities have already been described. The three remaining animals had not experienced language training per se, but they did have a history of conditional and numeric token training (Boysen, 1993; Boysen \& Berntson, 1989); perhaps importantly, prior to the matching study, they had been trained with symbols for the relations "same" and "different." Specifically, the chimpanzees were rewarded for choosing a heart-shaped symbol presented on a touch screen after being shown a pair of identical objects or their pictorial representations (i.e., if AA, then $\boldsymbol{V}=\mathrm{S}+$ ); when presented with a pair of nonidentical objects, the chimpanzees were rewarded for choosing a diagonal form on the touch screen (i.e., if $\mathrm{QM}$, then / = S+). This conditional discriminative performance transferred to novel objects and pictures.

Later, and in the absence of the symbols, the same animals were tested on a series of physical and analogical matching problems. Correct choices on physical matching trials were differentially rewarded, whereas correct analogical matches were nondifferentially rewarded (i.e., all choices were reinforced). The chimpanzees' overall performances on the physical matching problems were well above chance (i.e., $83.6 \%$ to $87.5 \%$ ). Moreover, all three animals spontaneously matched the analogical relations and their overall performance levels (i.e., $80.1 \%$ to $87.5 \%$ correct) were equivalent to those of Sarah. As in Sarah's case, there was no evidence that perceptual or associative factors mediated the chimpanzees' analogical matching behaviors (Thompson et al., 1997).

In another study, infant chimpanzees lacking any experience with a symbolic token system were presented with matching-to-sample tasks. After first being trained to match with only a lock and a cup, these chimpanzees successfully matched a variety of novel objects on the very first testing trial (Oden, Thompson, \& Premack, 1988). Despite this evidence of their having acquired a broadly and spontaneously construed matching concept, these same chimpanzees nevertheless failed throughout a variety of training conditions to match pairs of objects on the basis of their analogical relatedness of identity (e.g., a pair of locks matches a pair of cups, but not a paired eraser and ball) or nonidentity (e.g., a paired clock and shoe matches a paired eraser and ball, but not a pair of cups). In this regard, the performance of these chimpanzees did not differ from what Premack had reported previously for language-naïve chimpanzees.

Thompson and his colleagues (Thompson et al., 1997; Thompson \& Oden, 2000) suggested that the results from symbol-sophisticated and symbol-naïve chimpanzees sup- 
port the hypothesis that prior experience with symbols for relations per se is sufficient for chimpanzees to immediately match higher-order analogical relations between relations (cf., Premack, 1988; Smith, King, Witt, \& Rickel, 1975). Providing concrete tokens to represent abstract same/different relations perhaps permits the covert recoding of the abstract (i.e., propositional) relations as imaginal representations of the tokens, thereby reducing the analogical matching task to one that is functionally equivalent to a physical same/different matching task.

\subsubsection{Do labels affect children's use of analogical simi- larity?}

The previous discussion of Sarah and the other symboltrained chimpanzees highlights the powerful catalytic effects of symbolic labels. If we are to group humans with chimpanzees, then presumably human children might likewise be affected by the presence of labels. Evidence indicating that is the case was reported by Rattermann and her colleagues (Rattermann \& Gentner, 1998; Thompson, Rattermann, \& Oden, 2001).

Results from one such study which examined children's analogical reasoning abilities suggest that the presence of labels is a powerful catalyst for the use of relational similarity. Rattermann and Gentner (1998) found that, without relational labels, the performance of 3-year-olds was comparable to that of non-token trained chimpanzees. The researchers also found that older children (5-year-olds) were quite adept at an explicit analogical reasoning task, much like Sarah and the other symbol-trained chimpanzees. Interestingly, the presence of a set of simple labels improved the performance of the 3-year-olds to a level comparable to that of the 5-yearolds - an improvement in performance akin to that found in label/token-trained versus non-label/token-trained chimpanzees.

Rattermann and Gentner (1998) used an explicit analogical reasoning task that pitted perceptual sameness against analogical sameness. Using a technique called cross-mapping, 3-, 4-, and 5-year-olds were shown two triads of objects, each arranged in monotonically decreasing size (e.g., $432 \rightarrow 321$ ) in a fan-like pattern. One set belonged to the experimenter and one set belonged to the child. The child watched the experimenter place a sticker under an object in her set and then searched in his own set for a sticker hidden under the corresponding object. Because of the cross-mapping, matches based on perceptual sameness (e.g., $3->3$ ) competed against matches based on analogical sameness (e.g., $3 \longrightarrow$ ).

To further examine the effects of perceptual sameness, Rattermann and Gentner (1998) manipulated the "richness" of the objects forming the triads; for half the children the triads were formed with simple, sparse objects which minimized perceptual sameness, whereas for the other children the triads were formed with rich, complex objects that enhanced perceptual sameness. The child received feedback for the correct answer, which was always based on analogical sameness. The results showed both a strong developmental change and an effect of object complexity: 3-year-olds produced 54\% relational responses with the sparse stimuli and $32 \%$ with the rich stimuli, whereas 5 -year-olds produced $95 \%$ relational responses with the sparse stimuli and $68 \%$ with the rich stimuli.

To examine the effects of labels on young children's use of analogical sameness, Rattermann and Gentner (1998) taught a group of 3-year-olds to use the relational labels "Daddy/ Mommy/Baby," which conveyed the relation of monotonic change in, for example, a 'family' set of teddy bears or toy penguins. When the labels were used on each trial, 3-yearolds were $84 \%$ correct, performing comparably to the 5year-olds in the original task. The beneficial effects of learning relational labels were not dependent on direct modeling. After experience with the "Daddy/Mommy/Baby" labels, 3 -year-olds maintained much of their gain $(57 \%)$ when they were given new stimuli on which no labels were used. Indeed, 3 -year-olds who returned 4 to 8 weeks after the initial session produced significantly more correct relational responses (62\%) than a control group without label experience $(28 \%)$.

These experiments thus demonstrate that language (symbolic labeling) can facilitate relational representation in young children and that it does so, as suggested, by "providing an invitation to form comparisons and further, to provide an index for stable memory encoding of the newly represented relational structure (Rattermann \& Gentner, 1998, p. 280)."

\subsubsection{Do labels affect categorical analogical equivalence judgments by monkeys?}

Might explicit training with conditional cues symbolizing relational sameness and difference catalyze the ability of monkeys to detect and to judge the categorical equivalence of analogical relations as it had for children and chimpanzees? Results from a pilot experiment and extensive followup study suggest not (Washburn, Thompson \& Oden, 1997; Thompson, Oden, \& Washburn, in preparation).

Similar to the chimpanzees in the study of analogical matching, the test-sophisticated macaque monkeys in these experiments were trained to use a joystick to move a cursor to a circle stimulus displayed on a computer monitor following their exposure to a pair of computer-generated stimuli, provided they instantiated an 'identity' relation (e.g., if AA, then $->\mathrm{O}=\mathrm{S}+$ ). Choice of an alternative triangle cue was 


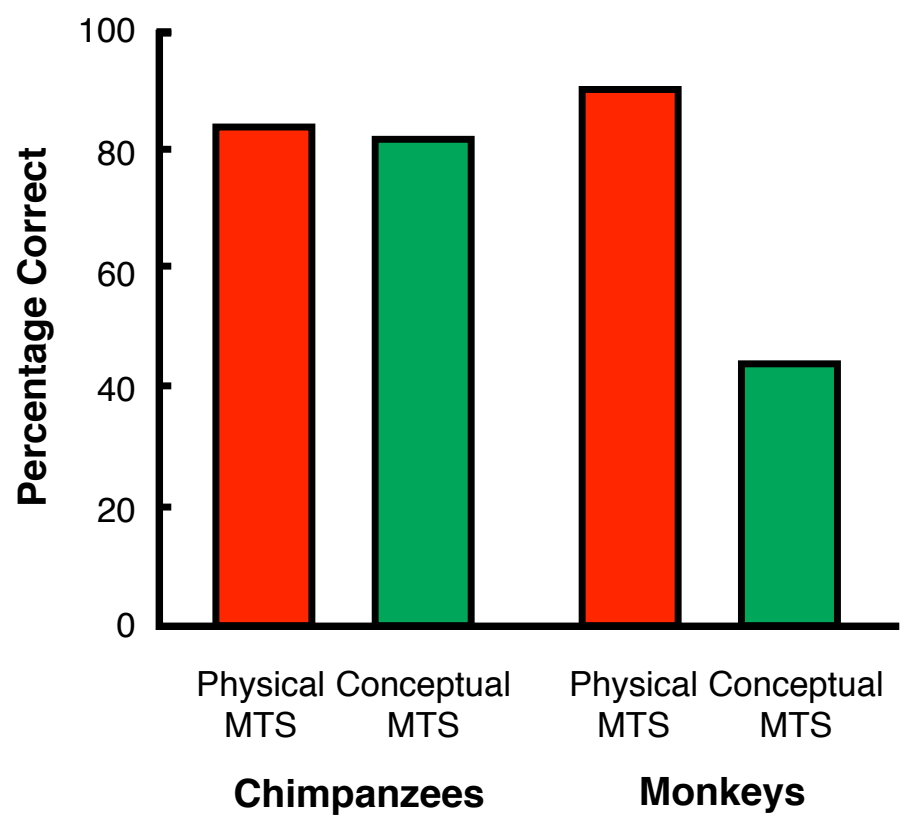

Figure 8. Physical and conceptual (i.e., analogical) matching to sample by chimpanzees (Pan troglodytes) and rhesus macaque monkeys (Macaca mulatta). (Adapted from Washburn, Thompson \& Oden, 1997.)

correct following presentations of a pair of stimuli instantiating a nonidentity relation (e.g., if $C D$, then $\rightarrow \boldsymbol{\Delta}=\mathrm{S}+$ ). The monkeys then transferred their performance to novel exemplars of the identity and nonidentity relations.

Subsequently, however, as shown in Figure 8, the monkeys' analogical matching performances, unlike those of the chimpanzees, remained at chance levels in the absence of the conditional $\mathrm{O}$ and $\boldsymbol{\Delta}$ cues. Nevertheless, there was no difference in the ability of monkeys or chimpanzees to match items on the basis of their physical features (i.e., color, shape, and size).

How might one account for the success of the monkeys in generalizing the initial conditional discrimination between identity pairs and the $\mathrm{O}$ cue, on the one hand, and that between nonidentity stimulus pairs and the $\boldsymbol{\Delta}$ cue, on the other? One possibility is that choice of the $\mathrm{O}$ and $\mathrm{p}$ cues was a function of the matching or nonmatching outcome of a computational operation performed on individual withinpair items rather than on the perception of relational identity or nonidentity (Thompson \& Oden, 2000; Thompson, Oden, \& Washburn, in preparation). Application of matching and nonmatching operators is likely to occur in all nonhuman primates, as well as in mammals and birds (cf., Thompson, 1995; Thompson \& Oden, 2000).

How might one account for these disparities in performance across species and between tasks? As described below, both adult and infant macaque monkeys, contrary to chimpanzees and children, appear to be perceptually insensitive to relational equivalencies as measured in implicit detection tests (see Thompson \& Oden, 1996, 2000). Hence, presumably the $\mathrm{O}$ and $\boldsymbol{\Delta}$ cues could not acquire symbolic referential meaning for the relations same and different as hypothesized for children and chimpanzees.

\subsubsection{Implicit or tacit detection of analogical relations by children and chimpanzees}

Karl Lashley (1929) claimed that, "The use of symbols depends upon the recognition of similarity and not the reverse." As described below, there are good reasons from studies of children, chimpanzees, and monkeys to accept his claim. Evidence for the differential capacities of human and chimpanzee infants, as well as adult and infant rhesus monkeys (Macaca mulatta), to implicitly or tacitly detect analogical relations without experimenter direction comes from studies measuring either visual gaze or object handling in preference-for-novelty tasks.

Tyrrell, Stauffer, and Snowman (1991) presented 7-monthold human infants with a preference-for-novelty task in order to test their ability to tacitly detect analogical similarity. Infants were first familiarized with a pair of objects that instantiated either the relation of same (AA) or the relation of different (BC) depending on the experimental condition. After this familiarization trial, infants were presented with two novel object pairs, instantiating same and different relations, $\mathrm{DD}$ and $\mathrm{EF}$, respectively. Using gaze duration as their dependent measure, Tyrrell et al. found that the infants looked significantly longer at the objects instantiating the relationship that was novel compared to that relationship with which they had been familiarized on the first trial; so, following familiarization to an identity pair (AA), the infants looked longer at EF than at DD on the test trial. From this evidence, Tyrrell et al. concluded that infants as young as 7-months of age can spontaneously detect same and different relations. The finding was important if only because it seemed counterintuitive given that children cannot reliably make analogical equivalence judgments until they are 3 to 5 years of age or older (cf., House, Brown, \& Scott, 1974; Piaget, Montangero, \& Billeter, 1977; Tyrrell, Zingaro, \& Minard, 1993).

Prior to the Tyrrell et al. (1991) study, Oden, Thompson, and Premack (1990) had reported that measures of object handling time in a preference-for-novelty study with infant chimpanzees pointed to a disparity between an organism's capacities to implicitly or tacitly detect relational sameness and difference as opposed to its capacity to explicitly judge analogical equivalence relations. The animals in this study were the same four "language-naïve" chimpanzees that had consistently failed to match analogical relations instantiated by pairs of objects, despite the evidence of their possessing a 
broadly construed matching concept based on physical identity (Oden, et al., 1988).

On the implicit (i.e., uninformed) preference-for-novelty task, these same animals handled an object for a shorter time if, on a prior familiarization trial, they had handled the same object than if they had handled a different object. This finding is consistent with that obtained in the physical matching task. But, in contrast to their failure to match analogical relations, measures of differential handling times by these same animals indicated that they tacitly detected the relational sameness or difference between pairs of objects. The chimpanzees handled a pair of objects longer if it instantiated a novel same/different relation rather than a familiar same/different relation. So, why did these young chimpanzees fail to categorically match analogical relations? Perhaps they lacked requisite exposure to the presumed facilitative effects of symbol training and labeling on the relational recoding that was experienced by other chimpanzees and children (e.g., Rattermann \& Gentner, 1998; Thompson et al., 1997).

Reviewing the evidence, Thompson and Oden (2000) concluded that, unlike chimpanzees and human children, neither adult nor infant macaque monkeys spontaneously or tacitly detect the equivalence of analogical relations between relations. This disparity across phylogenetic orders of old-world primates held regardless of the behavioral task (preference-for-novelty or habituation/dishabituation) and whether visual gaze or object handling was the dependent measure. What could account for the monkeys' failure to tacitly detect analogical relations instantiated by pairs of like and unlike stimuli in preference-for-novelty and habituation/ dishabituation tasks? Interestingly, there was some evidence from these experiments of longer looking times to stimulus variability; despite their tacit insensitivity to analogical sameness or difference across conditions, the monkeys often looked longer at stimulus pairs instantiated by two nonidentical objects than they looked at stimulus pairs instantiated by two identical objects. That is, two different objects (i.e., reflecting variability) were more interesting than one object repeated (i.e., reflecting no variability). Hence, one possibility for the animals' failure to tacitly detect analogical sameness and difference with two-item samples may be related to the difficulty to capitalize on their capacity to discriminate entropy differences with stimuli comprising only two items.

Recall that Young and Wasserman (2001, Experiment 1) reported that not all humans responded categorically to mixtures of same and different stimulus arrays. Like the response profiles of nonhumans, those of some college students were continuous. If, as suggested in the above discussion, all organisms scale the stimuli in terms of entropy, then perhaps the dichotomy between monkeys and chimpanzees in their relational matching performance with stimulus pairs reflects differences in their respective same/different variability thresholds; the latter chimpanzees--like most humans, but unlike monkeys--may set their decision threshold for entropy near zero. If, as further suggested above, the provision of symbols for "same" and "different" cognitively leverages continuous entropy into categorical judgments, then perhaps combining "entropy infused" stimulus variability with conditional symbol training might provide monkeys with the requisite environmental scaffolding for shifting their thresholds, thereby enabling acquisition of categorical same/different discriminations with stimulus pairs.

\subsubsection{Entropy-infused conditional discrimination training with monkeys}

Flemming and his colleagues recently explored in macaque monkeys the possible synergistic scaffolding effect of combining "entropy infused" stimulus variability (rows of same or different stimuli) with conditional symbol training on the subsequent acquisition of categorical two-alternative same/different discriminations (Flemming, Beran, \& Washburn, 2005; Flemming et al., 2007).

As had other investigators (Thompson et al., in preparation; Washburn et al., 1997), these researchers first found that their animals failed to discriminate relations between pairs of 2-item stimuli. However, in a subsequent experiment, the same animals rapidly learned to discriminate horizontal 8-element arrays that were all the same from 8-element arrays that were all different. The background color of the display, on which the two rows of icons appeared, served as a conditional cue as to whether the same or the different row was the (randomly determined) S+ on any given trial. Hence, if the background was pink, then the monkeys were rewarded for moving a joystick-controlled cursor to the same array, whereas if the background was black, then they were rewarded for contacting the different array with the cursor. The number of items per row was then reduced in decrements of 2 (i.e., 8 to 6 to 4 to 2). In each case, the monkeys reached a criterion of $80 \%$ or better correct in fewer than 50 trials.

In the next experiment, the monkeys were tested on an analogical matching task with pairs of same or different icons serving as the sample and choice alternatives. All of the individual icons from which pairs were constructed were physically disparate and, as in the previous experiment, the background color of the display served as the conditional cue signaling whether the correct choice matching the sample relation was same or different.

Four of five monkeys reached the $80 \%$ or better performance criterion in fewer than 200 trials. These encouraging results suggested that conjoining entropy with symbol training had indeed provided the animals with the requisite 
environmental scaffolding to shift their discrimination of relational sameness and difference from dimensional to categorical control.

In subsequent testing sessions, the conditional cue was present on the first 100 trials and then removed, while the sample and choice stimuli appeared on a white background. Whereas performance with the conditional cue present was always around $95 \%$ correct or better, performance dropped immediately to around $55 \%$ correct when the conditional cue was not present on a matching trial, and it remained at that level for 300 to 500 within-session trials. Over the course of 6,000 trials of analogical matching without the conditional cue present, none of the monkeys showed any marked improvement in performance. Hence, as in the experiments conducted by Washburn et al. (1997) and Thompson et al. (in preparation), the performance of these old-world monkeys on the analogical matching task deteriorated with the removal of the cognitive scaffolding provided by the symbolic conditional discriminative cue originally conjoined with entropy or its absence.

Here, it might be observed that the successful relational matching-to-sample performance of baboons (Fagot et al., 2001) was preceded by extensive prior experience with firstorder same-different discrimination training, which entailed distinctive visual symbols representing "same" and "different" report responses (Wasserman et al., 2001). Those symbols and the "same" and "different" report responses were removed during relational matching-to-sample training, but the displays in both first-order and second-order relational training contained 16 visual items.

\subsubsection{Summary}

The evidence reviewed thus far from both human and nonhuman primate studies suggests that entropy can play an important role in the discrimination of relational sameness and difference. However, unlike the case for chimpanzees and children, providing macaque monkeys with concrete tokens or conditional cues to represent analogical relations between relations apparently does not catalyze their ability to make categorical analogical equivalence judgments instantiated by only pairs of like and unlike items (see also, for example, Kuczaj \& Hendry, 2003; Savage-Rumbaugh, 1986; Thompson \& Oden, 1993). The root of this capacity may be the ability of both chimpanzees and children, but, thus far, not monkeys, to tacitly detect relations between relations instantiated by pairs of items spontaneously and early in life. This tacit perceptual ability precedes the categorical judgment of analogical equivalences.

The additional suggestion that the explicit (i.e., judgment) expression of otherwise implicit or tacit perceptual competencies is catalyzed by some form of re-coding via linguis- tic labeling or concrete symbolic system was independently proposed by Clark and Thornton (1997) in their computational approach to uninformed learning. They found that their artificial intelligent systems 'ran aground' in exactly the same class of tasks used with children and nonhuman primates unless their connectionist net was provided with some external means of reducing the search space.

Clark and Thornton's (1997) findings imply that experience using external symbol structures transforms the shape of the computational spaces that must be negotiated in order to solve abstract problems like analogical reasoning. This conclusion implies that analogy requires complex computational processes, consistent with the prevailing views of researchers who study analogical reasoning by humans (e.g., Gentner, 1998; Gentner, Holyoak, \& Boikov, 2001; Halford, 1992; Holyoak \& Thagard, 1997).

\subsection{Formal Analogical Reasoning by Sarah, a Chimpan- zee}

Perhaps the most convincing evidence of formal analogical reasoning by a nonhuman animal in a cognitive manner analogous to that claimed for humans comes from Sarah, a chimpanzee (Pan troglodytes). Early evidence of Sarah's capacity for making analogical judgments was reflected in her performance on formal analogical problems involving geometric forms and functional relationships between everyday objects (Gillan, Premack, \& Woodruff, 1981). Additional evidence of this animal's capacities for analogical problem solving with geometric forms included not only the completion of partially constructed analogies, but also the spontaneous undirected construction of analogies from geometric elements (Oden, Thompson, \& Premack, 2001).

In an early set of experiments, Gillan et al. (1981) presented Sarah with four simple geometric forms placed on a display board in a $2 \times 2$ format (as shown in Figure 9). The two items on the left-hand side instantiated the base relation and the two items on the right-hand side instantiated the target relation, which was either the same as or different from that of the base relation. In either case, physically different geometric forms (i.e., circles vs. squares of various sizes) represented the base and target relations. If the base and target relations were the same (i.e., a correct analogy), then Sarah judged them so by placing the plastic token for the concept 'same' from her artificial language between the pairs of forms. If the base and target relations were not the same and hence did not represent a correct analogy, then Sarah judged them so by placing the plastic token for the concept 'different' between the pairs of forms (Premack \& Premack, 1972; Premack, 1976).

In other experiments, Sarah was presented with a complete base relation on the left-hand side of the display board, but 


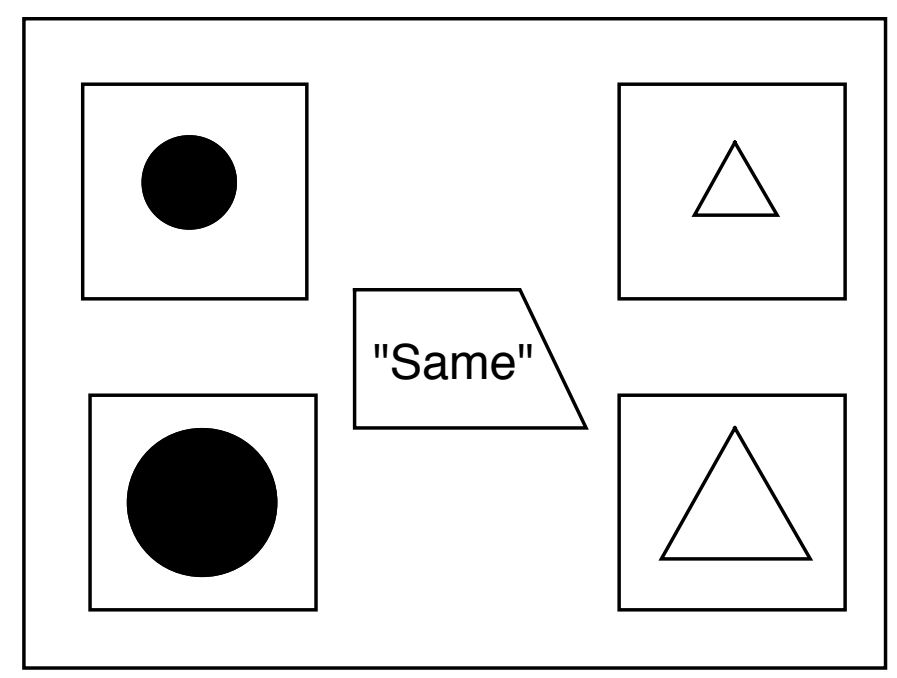

Figure 9. The $2 \times 2$ matrix format used in completion and construction of geometric analogies by Sarah, a chimpanzee (Pan troglodytes). (Adapted from Gillan, Premack, \& Woodruff, 1981.)

with only one item on the right-hand side. The plastic token for 'same' was placed between the base and the incomplete target. Sarah successfully completed the target relation by choosing from two alternative forms the one that produced an analogy. Sarah further demonstrated her capacity in the Gillan et al. (1981) study by both judging and completing analogical relations based on the functional properties of objects, such as their capacity to open or to mark other objects. For example, a can opener holds the same functional relation to a can of vegetables as does a key to a padlock.

Gillan et al. (1981) interpreted Sarah's performance on both geometric and functional analogy problems as evidence of her ability to establish the higher-order analogical relationships "same" or "different" between the two sides of the analogy by first comparatively assessing the lower-order relationships within each side and then comparing them. However, as described in Oden et al. (2001), at least some of Sarah's apparent analogical-based performances could have been achieved by less sophisticated strategies, including, for example, featural matching rules and similarity, if not identity, judgments.

Oden et al. (2001) further explored the boundaries of Sarah's analogical reasoning capacities in a series of experiments that again used simple geometric forms. In two of the four conditions of this study, Sarah had to complete partially constructed analogies from either two or three alternatives, similar to the task used by Gillan et al. (1981). In the other two conditions, Sarah had to construct analogical relations by placing geometric forms from a randomized group of four or five alternatives onto the initially empty display board. This latter task is arguably more demanding, as it required
Sarah first to seek unspecified relations among the available geometric elements and then to judge the analogical equivalence of these relations.

When presented with four alternatives, Sarah proceeded to arrange them into valid analogies on 76\% (28/37) of those trials in which her first choices had created potential analogies. When presented with five alternatives, Sarah was required not simply to arrange four items into an analogy, but to select from among the five items those four with which an analogy could be constructed. In this condition, Sarah constructed analogies on 15 out of 72 trials (21\%). This performance level was substantially lower than in the other conditions, but it was still statistically different from chance [ $20 \%$ (the correct four out of five items) x 33\% (the percentage of patterns of the 4 items that formed an acceptable analogy) $=$ $6.7 \%]$.

The results from the Oden et al. (2001) study not only confirmed Gillan et al.'s (1981) earlier evidence that Sarah can solve analogy problems, but they provided new evidence that she could do so spontaneously; in no case, did Sarah ever attempt to use a less efficient associative strategy as can occur with children (Alexander et al., 1989).

\subsection{Broader Primate Categorical Analogy Perspectives}

Until recently, we did not know whether the "profound disparity' (Premack, 1978, 1983; Thompson \& Oden, 1996) in categorical analogical problem solving between humans and chimpanzees (Hominoidea), on the one hand, and oldworld monkeys (Cercopithecoidea), on the other, could be generalized to include categorical relations other than the 2item relations of identity and nonidentity (eg., $\mathrm{AA}=\mathrm{BB}$ and $\mathrm{CD}=\mathrm{EF}$ but $\mathrm{AA} \neq \mathrm{EF}$ ) or to new-world monkeys (Ceboidea), such as capuchins (Cebus sp.). If capuchins, like old-world monkeys were found to be handicapped with respect to their categorical analogical matching abilities this would suggest that analogical reasoning is a derived cognitive characteristic in the Hominoidea (apes and humans). Results from studies with baboons and capuchin monkeys on a categorical above/ below spatial matching task by, respectively, Dépy, Fagot, and Vauclair (1999) and Spinozzi, Lubrano, and Truppa (2004) suggest that unqualified acceptance of this hypothesis may well be premature.

In these studies baboons (Papio papio) (Dépy et al., 1999) and tufted capuchin monkeys (Cebus apella) (Spinozzi et al., 2004) matched pairs of "bar and dot" stimuli on the basis of the relative above and below location of the two constituent elements. For example, if the sample consisted of a dot above the horizontal bar, then the correct matching alternative likewise involved a dot above a horizontal bar and the incorrect alternative involved a dot below a horizontal bar. Conversely, the dot below the bar was correct if the sample 
consisted of a dot below a horizontal bar.

After acquiring the initial above/below discrimination, the baboons and capuchins transferred their performances to stimuli in which the distances between the bar and dot in the response alternatives differed from that of the sample and in which the absolute spatial location of the matching and nonmatching stimuli varied on the stimulus display board. Further evidence of the conceptual ability of the capuchins on this task was inferred from the transfer of their matching performances to problems in which the shape of either the located object (i.e., the dot) or the reference object (i.e., the bar) was changed. For example, if the sample located object was a star, then a triangle was the locator in the correct alternative. Likewise, if the reference object in the sample was a horizontal bar, then it was a vertical column in the correct alternative (Spinozzi et al., 2004).

These results from the relational spatial matching task are interesting on several counts. The transfer results in particular provide perhaps the first instance of relational matching by monkeys in a task in which the sample and alternative exemplars comprised only two items, as is the case in the analogical same/different matching of nonspatial identity and nonidentity by symbol sophisticated chimpanzees. There are, however, important differences in the two types of relational matching tasks. First, the nature of the spatial task mandates that at least one of the two physical features (locator or reference object) instantiating the spatial relation remains invariant across the sample and both the correct and incorrect response alternatives; in 2-item analogical same/ different matching, there are no physical similarities between any of the items instantiating the relations of identity and nonidentity. Second, a continuous perceptual dimension is present in those transfer cases where the physical distance between the locator and reference objects are manipulated.

The factors noted above may well have critical environmental scaffolding effects on the acquisition of the relational spatial matching task by the baboon and capuchin monkeys. Perhaps, for example, the unavoidable partial physical invariance across the sample and both alternative exemplars helps to focus an animal's attention away from physical cues per se and toward the dimensional relational cues, thereby reducing the computational search space as suggested by Clark and Thornton (1997). If so, then one might wonder whether the categorical relational matching performance of the monkeys would transfer to other relations including the judgment of pairwise identity and nonidentity as observed in symbol sophisticated chimpanzees and most humans.

At the very least, the results of Spinozzi et al. (2004), when considered together with those of Wasserman and his colleagues for pigeons and baboons, suggest a greater degree of behavioral continuity in the evolution of relational concepts - and perhaps process too - than might be suspected from an anthropocentric focus on the Hominoidea (apes and humans) alone.

\subsection{Summary}

When it comes to relations between relations in the form of analogies, there appear to be differences among species. Pigeons and monkeys can learn to select a display containing a set of several identical icons when the sample set contains a different set of identical icons and to select a display containing a set of all different icons when the sample set contains a different set of all different icons; however, evidence of the use of an analogy when the sets of stimuli are reduced to only pairs of identical or nonidentical items appears to occur reliably in only apes (especially one ape, Sarah) and children. The failure of monkeys and pigeons to succeed at this task when the minimal number of stimuli is used may be attributed to the inability of these animals to acquire symbolic referential meaning for categorical relations of identity and nonidentity. Their greater dependence on the entropy of the various displays may also play a role. However, evidence that monkeys can acquire a generalized 'above' or 'below' spatial analogy matching task involving displays of only two constituent elements (e.g., a dot and a horizontal line) suggests that monkeys may be able to acquire rudimentary versions of two-stimulus analogies.

\section{Conclusions}

"As in all psychology, the vast majority of research done on concepts has used American undergraduate students as its subjects. Assuming that the principles of concept learning are fairly constant, there is no harm done. But, to the degree that they aren't, then this fact can only hide the full richness of conceptual structures." (Murphy, p. 481, 2002).

Animals have evolved various behavioral capacities that, when studied under the appropriate conditions, rival or even exceed those of humans. No one would question the sense of smell of the bloodhound or the strength of an elephant. And, no one would argue that humans are inherently better at navigation than pigeons or migrating birds. Often, however, we assume that our conceptual ability is not only better than that of other animals, but that it is unique to our own species. Yet, other species have undoubtedly had to overcome environmental problems that required the deployment of an assortment of cognitive processes; if asked in the appropriate way, then these animals too can provide convincing evidence of their conceptual abilities.

In the present article, we have tried to present some of the evidence for the learning of perceptual, associative, and relational concepts by animals. We cannot say that nonhu- 
man animals have cognitive capacities that are equivalent to those of adult humans; but, we do believe that there is now good evidence that many species of animals are likely to have some of the same conceptual abilities that have typically been reserved exclusively for humans.

Why should scientists who focus on human concept learning care about these research efforts? In the first place, a truly inclusive science of cognition should center on the processes and functions of perceiving, learning, thinking, reasoning, planning, remembering, and acting, regardless of the systems performing those operations. To be sure, a strong culture of comparing a carbon-based system (human beings) with a silicon-based system (digital computers) is now well established. But, does it not make equally good, if not better, sense to compare humans to a variety of other carbon-based systems represented by living animal species that vary with respect to not only their historical and situational (phylogenetic and ecological) relatedness, but also their diverse neural organizations within and between taxa (Dehaene, Duhamel, Hauser \& Rizzolatti, 2005; Emery, 2006; Morino, 2004)?

The evolution of intelligence is the key organizing idea of comparative cognition, whose importance to cognitive science cannot be overstated. Common behavioral competencies may mean common origins - either by virtue of homology (shared ancestry) or homoplasy (convergent and parallel evolution) - and common origins may mean common mechanisms. Thus, research in comparative cognition importantly informs the work of those interested in both the evolution and physiological/neural underpinnings of cognition.

We hope that these thoughts and this review of current research in the comparative cognition of conceptualization will deepen our understanding of the design and function of intelligent systems. If we are ever to fully understand the human mind, then knowing how it is similar to and different from other animal minds will be indispensable.

\section{References}

Adams, B. J., Fields, L., \& Verhave, T. (1993). Formation of generalized equivalence classes. Psychological Record, 43, 553-566.

Alexander, P. A., Wilson, V. L., White, C. S., Fuqua, J. D., Clark, G. D., Wilson, A. F., \& Kulikowich, J. M. (1989). Development of analogical reasoning in 4- and 5-year-old children. Cognitive Development, 4, 65-88. doi:10.1016/0885-2014(89)90005-1

Anderson, J. R. (1991). The adaptive nature of human categorization. Psychological Review, 98, 409-429. doi:10.1037/0033-295X.98.3.409

Astley, S. L., \& Wasserman, E. A. (1992). Categorical discrimination and generalization in pigeons: All negative stimuli are not created equal. Journal of Experimental Psychology: Animal Behavior Processes, 18, 193-207. doi:10.1037/0097-7403.18.2.193

Aust, U., \& Huber, L. (2002). Target-defining features in a "people-present/people-absent" discrimination task by pigeons. Animal Learning \& Behavior, 30, 165-176.

Bekoff, M., Allen, C., \& Burghardt, G. M. (2002). The cognitive animal. Cambridge, MA: MIT Press.

Bhatt, R. S. (1988). Categorization in pigeons: Effects of category size, congruity with human categories, selective attention, and secondary generalization. Unpublished doctoral dissertation, University of Iowa, Iowa City.

Bhatt, R. S., Wasserman, E. A., Reynolds, W. F., Jr., \& Knauss, K. S. (1988). Conceptual behavior in pigeons: Categorization of both familiar and novel examples from four classes of natural and artificial stimuli. Journal of Experimental Psychology: Animal Behavior Processes, 14, 219-234. doi:10.1037/0097-7403.14.3.219

Blaisdell, A. P., \& Cook, R. G. (2005). Two-item same-different concept leaning in pigeons. Learning \& Behavior, 33, 67-77.

Bovet, D., \& Vauclair, J. (1998). Functional categorization of objects and their pictures in baboons (Papio anubis). Learning \& Motivation, 29, 309-322.

doi:10.1006/lmot.1998.1009

Bovet, D., \& Vauclair, J. (2001). Judgment of conceptual identity in monkeys. Psychonomic Bulletin \& Review, 8, 470-475.

Boysen, S. T. (1993). Counting in chimpanzees: Nonhuman principles and emergent properties of number. In S. T. Boysen, \& E. J. Capaldi, (Eds.), The development of numerical competency: Animal and human models. Hillsdale, NJ: Erlbaum Associates.

Boysen, S. T., \& Berntson, G. G. (1989). Numerical competence in a chimpanzee (Pan troglodytes). Journal of Comparative Psychology, 103, 23-31. doi:10.1037/0735-7036.103.1.23

Boysen, S. T., Berntson G. G., Shreyer, T. A., \& Quigley, K. S. (1993). Processing of ordinality and transitivity by chimpanzees (Pan troglodytes). Journal of Comparative Psychology, 107, 208-215. doi:10.1037/0735-7036.107.2.208

Bryant, P. E., \& Trabasso, T. (1971). Transitive inference and memory in young children. Nature, 232, 456-458. doi: $10.1038 / 232456 \mathrm{a} 0$

Carey, S. (1978). The child as word learner. In M. Halle, G. Miller, \& J. Bresnan (Eds.), Linguistic theory and psychological reality (pp. 264-293) Cambridge, MA: MIT Press.

Chater, N. \& Heyes, C. (1994). Animal concepts: Content and discontent. Mind \& Language, 9, 210-246. doi:10.1111/j.1468-0017.1994.tb00224.x

Clark, A., \& Thornton, C. (1997). Trading spaces: Computation, representation, and the limits of uniformed learning. Behavioral and Brain Sciences, 20, 57-90. 
Clement, T. S., \& Zentall, T. R. (2003). Choice based on exclusion in pigeons. Psychonomic Bulletin \& Review, 10, 959-964.

Colwill, R. M. (1984). Disruption of short-term memory for reinforcement by ambient illumination. Quarterly Journal of Experimental Psychology, 36B, 235-258.

Cook, R. G. (Ed). (2001). Avian visual cognition. Retrieved from http://www.comparativecognition.org/.

Cook, R. G., \& Wasserman, E. A. (2006). Relational learning in pigeons. In E. A. Wasserman, \& T. R. Zentall (Eds.), Comparative cognition: Experimental explorations of animal intelligence (pp. 307-324). London: Oxford University Press.

Cook, R. G., \& Wasserman, E. A. (in press). Learning and transfer of relational matching-to-sample by pigeons. Psychonomic Bulletin \& Review.

Cook, R. G., Wright, A. A., \& Kendrick, D. F. (1990). Visual categorization by pigeons. In M. L. Commons, R. J. Herrnstein, S. M. Kosslyn, \& D. M. Mumford (Eds.), Quantitative analyses of behavior: Pattern recognition, Vol. VIII (pp. 187-214). Hillsdale, NJ: Erlbaum.

Couvillon, P. A., \& Bitterman, M. E. (1992). A conventional conditioning analysis of "transitive inference" in animals. Journal of Experimental Psychology: Animal Behavior Processes, 18, 308-310. doi:10.1037/0097-7403.18.3.308

Cummins, D., \& Allen, C. (1998). The Evolution of Mind. New York, NY: Oxford University Press.

Davis, H. (1992). Transitive inference in rats (Rattus norvegicus). Journal of Comparative Psychology, 106, 342349. doi:10.1037/0735-7036.106.4.342

Dehaene, S., Duhamel, J. R., Hauser, M. D., \& Rizzolatti, G. (Eds.). (2005). From monkey brain to human brain: A Fyssen foundation symposium. Cambridge, MA: MIT Press.

Delamater, A. R., \& Joseph, P. (2000). Common coding in symbolic matching tasks with humans: Training with a common consequence or antecedent. Quarterly Journal of Experimental Psychology B: Comparative and Physiological Psychology, 53B, 255-274.

doi:10.1080/027249900411182

Delius, J. D. (1994). Comparative cognition of identity. In International perspectives on psychological science, Vol. 1: Leading themes (pp. 25-40). Bertelson, P \& Eelen, P. (Eds.). Hillsdale, NJ: Lawrence Erlbaum.

Dépy, D., Fagot, J., \& Vauclair, J. (1999). Processing of above/below categorical spatial relations by baboons (Papio papio). Behavioural Processes 48, 1-9.

doi:10.1016/S0376-6357(99)00055-8

De Rose, J. C. (1996). Controlling factors in conditional discrimination and tests of equivalence. In T. R. Zentall \& P. M. Smeets (Eds.), Stimulus class formation in humans and animals (pp. 253-278). Amsterdam: Elsevier.

doi:10.1016/S0166-4115(06)80112-3
Dixon, L. S. (1977). The nature of control by spoken words over visual stimulus selection. Journal of the Experimental Analysis of Behavior, 27, 433-442.

doi:10.1901/jeab.1977.27-433

Edwards, C. A., \& Honig, W. K. (1987). Memorization and "feature selection" in the acquisition of natural concepts in pigeons. Learning and Motivation, 18, 235-260. doi:10.1016/0023-9690(87)90013-0

Emery, N. J. (2006). Cognitive ornithology: The evolution of avian intelligence. Philosophical Transactions of the Royal Society B., 361, 23-43.doi:10.1098/rstb.2005.1736

Fagot, J. (1999). Picture perception in animals. Cahiers de Psychologie Cognitive/Current Psychology of Cognition, 18, 5-6.

Fagot, J., Wasserman, E. A., \& Young, M. E. (2001). Discriminating the relation between relations: The role of entropy in abstract conceptualization by baboons (Papio papio) and humans (Homo sapiens). Journal of Experimental Psychology: Animal Behavior Processes, 27, 316328. doi:10.1037/0097-7403.27.4.316

Farthing, G. W., Wagner, J. W. Gilmour, S., \& Waxman, H. M. (1977). Short-term memory and information processing in pigeons. Learning and Motivation, 8, 520-532. doi:10.1016/0023-9690(77)90049-2

Fersen, L. v., Wynne, C. D. L., Delius, J. D., \& Staddon, J. E. R. (1991). Transitive inference formation in pigeons. Journal of Experimental Psychology: Animal Behavior Processes, 17, 334-341. doi:10.1037/0097-7403.17.3.334

Fetterman, J.G. (1996). Dimensions of stimulus complexity. Journal of Experimental Psychology:Animal Behavior Processes, 22, 3-18. 17, 334-341.

Flemming, T. M., Beran, M. J., \& Washburn, D. A. (March, 2005). Same vs. different or uniformity vs. chaos? Perception of abstract relations by Rhesus monkeys (Macaca mulatta). Proceedings of the International Conference on Comparative Cognition, Melbourne, FL.

Flemming, T. M., Beran, M. J., \& Washburn, D. A. (2007). Disconnect in concept learning by Rhesus monkeys ( $M a$ caca mulatta): Judgment of relations and relations-between-relations. Journal of Experimental Psychology: Animal Behavior Processes, 33, 55-63.

doi:10.1037/0097-7403.33.1.55

Frank, A. J., \& Wasserman, E. A. (2005). Associative symmetry in the pigeon after successive matching-to-sample training. Journal of the Experimental Analysis of Behavior, 84, 147-165. doi:10.1901/jeab.2005.115-04

French, R. M. (1995). The subtlety of sameness. Cambridge MA: MIT Press.

Fujita, K. (1987). Species recognition by five macaque monkeys. Primates, 28, 353-366. doi:10.1007/BF02381018

Fujita, K., \& Matsuzawa, T. (1986). A new procedure to study the perceptual world of animals with sensory reinforcement: Recognition of humans by a chimpanzee. Pri- 
mates, 27, 283-291. doi:10.1007/BF02382072

Gentner, D. (1998). Analogy. In W. Bechtel, \& G. Graham (Eds.), A companion to cognitive science (Blackwell companions to philosophy; 13) (pp. 107-113). Malden, MA: Blackwell.

Gentner, D., Holyoak, K. J., \& Kokinov, B. N. (2001). The analogical mind: Perspectives from cognitive science. Cambridge, MA: MIT Press.

Gillan, D. J. (1981). Reasoning in chimpanzees: II. Transitive inference. Journal of Experimental Psychology: Animal Behavior Processes, 7, 150-164.

doi: 10.1037/0097-7403.7.2.150

Gillan, D. D., Premack, D., \& Woodruff, G. (1981). Reasoning in the chimpanzee: I. Analogical reasoning. Journal of Experimental Psychology: Animal Behavior Processes, 7, 1-17. doi:10.1037/0097-7403.7.1.1

Gomez, J. C. (2004). Apes, monkeys, children, and the growth of mind. Cambridge, MA: Harvard University Press.

Grant, D. S. (1991). Symmetrical and asymmetrical coding of food and no-food samples in delayed matching in pigeons. Journal of Experimental Psychology: Animal Behavior Processes, 17, 186-193. doi:10.1037/0097-7403.17.2.186

Gray, L. (1966). Backward association in pigeons. Psychonomic Science, 4, 333-334.

Grosenick, L., Clement, T. S., \& Fernald, R. D. (2007) Are fish logical? Bystanders infer social rank by observation alone. Nature, 445, 429-432. doi:10.1038/nature05511

Halford, G. S. (1992). Analogical reasoning and conceptual complexity in cognitive development. Human Development, 35, 193-217.

Hampton, J. A. (1999). Concepts. In MIT Encyclopedia of the Cognitive Sciences. R.A. Wilson, \& F.C. Keil (Eds.), Cambridge, MA: The MIT Press (Bradford). pp 176-179.

Harnad, S. (Ed.). (1987). Categorical perception: The groundwork of cognition. Cambridge: Cambridge University Press.

Herrnstein, R. J. (1985). Riddles of natural categorization. Philosophical Transactions of the Royal Society, B308, 129-144. doi:10.1098/rstb.1985.0015

Herrnstein, R. J., \& de Villiers, P. A. (1980). Fish as a natural category for people and pigeons. In G. H. Bower (Ed.), Psychology of learning and motivation (pp. 59-95). San Diego, CA: Academic Press.

Herrnstein, R. J., \& Loveland, D. H. (1964). Complex visual concept in the pigeon. Science, 146, 549-551. doi:10.1126/science. 146.3643.549

Heyes, C., \& Huber, L. (2000). The evolution of cognition. Cambridge, MA: MIT Press.

Hogan, D. E., \& Zentall, T. R. (1977). Backward associative learning in the pigeon. American Journal of Psychology, 90, 3-15. doi:10.2307/1421635

Hogue, M.-E., Beaugrand, J. P., \& Lague, P. C. (1996). Co- herent use of information by hens observing their former dominants defeating or being defeated by stranger. Behavioural Processes, 38, 241-252.

doi:10.1016/S0376-6357(96)00035-6

Holyoak, K. J. (1984). Analogical thinking and human intelligence. In R. J. Sternberg (Ed.), Advances in the psychology of human intelligence (vol. 2, pp. 199-230). Hillsdale, NJ: Erlbaum.

Holyoak, K. J., \& Thagard, P. (1997). The analogical mind. American Psychologist, 52, 35-44.

Homa, D., Burruel, L., \& Field, D. (1987). The changing composition of abstracted categories under manipulations of decisional change, choice difficulty, and category size. Journal of Experimental Psychology: Learning, Memory, and Cognition, 13, 401-412.

Honig, W. K., \& Thompson, R. K. R. (1982). Retrospective and prospective processing in animal working memory. In G. H. Bower (Ed.), The psychology of learning and motivation, advances in research and theory. New York: Academic Press, 239-283.

Horne, P. J., \& Lowe, C. F. (1996). On the origins of naming and other symbolic behavior. Journal of the Experimental Analysis of Behavior, 65, 185-241.

doi:10.1901/jeab.1996.65-185

House, B. J., Brown, A. L., \& Scott, M. S. (1974). Children's discrimination learning based on identity or difference. In H. W. Reese (Ed.), Advances in child development and behavior, Vol. 9, New York: Academic Press.

Huber, L. (1999). Generic perception: Open-ended categorization of natural classes. In J. Fagot (Ed.). Picture perception in animals. Cahiers de Psychologie Cognitive/Current Psychology of Cognition, 18, 219-261.

Kaiser, D. H., Sherburne, L. M., Steirn, J. N., \& Zentall, T. R. (1997). Perceptual learning in pigeons: Decreased ability to discriminate samples mapped onto the same comparison in many-to-one matching. Psychonomic Bulletin \& Review, 4, 378-381.

Kaminski, J., Call, J., \& Fischer, J. (2004). Word learning in a domestic dog: Evidence for "fast mapping." Science, 304, 1682-1683. doi:10.1126/science. 1097859

Kastak, C. R., \& Schusterman, R. J. (2002). Sea lions and equivalence: Expanding classes by exclusion. Journal of the Experimental Analysis of Behavior, 78, 449-465. doi:10.1901/jeab.2002.78-449

Katz, J. S., \& Wright, A. A. (2006). Same-different abstractconcept learning by pigeons. Journal of Experimental Psychology: Animal Behavior Processes, 32, 80-86.

doi:10.1037/0097-7403.32.1.80

Katz, J. S., Wright, A. A., \& Bachevalier, J. (2002). Mechanisms of same/different abstract-concept learning by rhesus monkeys (Macaca mulatta). Journal of Experimental Psychology: Animal Behavior Processes, 28, 358-368. doi:10.1037/0097-7403.28.4.358 
Kuczaj, S. A. II, \& Hendry, J. L. (2003). Does language help animals think? In D. Gentner (Ed.), Language in mind: Advances in the study of language and thought, pp. 237275. Cambridge, MA: MIT Press.

Lashley, K. S. (1929). Learning: I. Nervous mechanisms in learning. In C. Murchison (Ed.), The foundations of experimental psychology, pp. 524-563. Worcester, MA: Clark University Press. doi:10.1037/11018-014

Lazareva, O. F., Smirnova, A. A., Bagozkaja, M. S., Zorina, Z. A., Rayevsky, V. V., \& Wasserman, E. A. (2004). Transitive responding in hooded crows requires linearly ordered stimuli. Journal of the Experimental Analysis of Behavior, 82,1-19. doi:10.1901/jeab.2004.82-1

Lazareva, O. F., Freiburger, K. L., \& Wasserman, E. A. (2004). Pigeons concurrently categorize photographs at both basic and superordinate levels. Psychonomic Bulletin and Review, 11, 1111-1117.

Lazareva, O. F., \& Wasserman, E. A. (in press). Categories and concepts in animals. In R. Menzel (Ed.), Learning and memory - A comprehensive reference. Vol. II: Behavioral approaches. Elsevier.

Lazareva, O. F., \& Wasserman, E. A. (2006). Effect of stimulus orderability and reinforcement history on transitive responding in pigeons. Behavioural Processes, 72, 161172. doi:10.1016/j.beproc.2006.01.008

Lazareva, O. F., Wasserman, E. A., Young, M. E. (2005). Transposition in pigeons: Reassessing Spence (1937) with multiple discrimination training. Learning and Behavior, 33, 22-46.

Mackintosh, N. J. (1994). Animal Learning and cognition (Handbook of perception and cognition, No. 3) San Diego, CA: Academic Press.

Marino, L. (2004). Cetacean Brain Evolution: Multiplication Generates Complexity. International Journal of Comparative Psychology, 17, 1-16.

Matsukawa, A., Inoue, S., \& Jitsumori, M. (2004). Pigeon's recognition of cartoons: Effect of fragmentation, scrambling, and deletion of elements. Behavioural Processes, 65, 23-34. doi:10.1016/S0376-6357(03)00147-5

McGonigle, B. O., \& Chalmers, M. (1977). Are monkeys logical? Nature, 267, 694-696. doi:10.1038/267694a0

Medin, D. L., \& Smith, E. E. (1984). Concepts and concept formation. Annual Review of Psychology, 35, 113-138. doi:10.1146/annurev.ps.35.020184.000553

Mercado, E. III., Killebrew, D. A., Pack, A. A., Macha, I. V. B., \& Herman, L. M. (2000). Generalization of "samedifferent" classification abilities in bottlenosed dolphins. Behavioural Processes, 50, 79-94. doi:10.1016/S0376-6357(00)00100-5

Murphy, G. L. (2002). The big book of concepts. Cambridge, MA: MIT Press (Bradford).

Oden, D. L., Thompson, R. K. R., \& Premack, D. (1988). Spontaneous transfer of matching by infant chimpanzees
(Pan troglodytes). Journal of Experimental Psychology: Animal Behavior Processes, 14, 140-145.

doi:10.1037/0097-7403.14.2.140

Oden, D. L., Thompson, R. K. R., \& Premack, D. (1990). Infant chimpanzees (Pan troglodytes) spontaneously perceive both concrete and abstract same/different relations. Child Development, 61, 621-631. doi:10.2307/1130949

Oden, D. L., Thompson R. K. R., \& Premack, D. (2001). Can an ape reason analogically? Comprehension and production of analogical problems by Sarah, a Chimpanzee (Pan troglodytes). In Gentner, D., Holyoak, K. J., \& Kokinov, B. N. (Eds.), Analogy: Theory and phenomena (pp. 472497). Cambridge, MA: MIT Press.

Pas-y-Miño, C. G., Bond, A. B., Kamil, A. C., \& Balda, R. P. (2004). Pinyon jays use transitive inference to predict social dominance. Nature, 430, 778-781.

doi:10.1038/nature02723

Pearce, J. M. (1988). Stimulus generalization and the acquisition of categories by pigeons. In L. Weiskrantz (Ed.), Thought without language (pp. 132-155). Oxford: Clarendon Press.

Pepperberg, I. M. (1987). Acquisition of the same/different concept by an African Grey parrot (Psittacus erithacus): Learning with respect to categories of color, shape, and materials. Animal Learning \& Behavior, 15, 423-432.

Piaget, J. (1928). Judgment and reasoning in the child. New York: Harcourt.

Piaget, J., Montangero, J., \& Billeter, J. (1977). La formation des correlats. In J. Piaget (Eds.), L'Abstraction reflechissante (pp. 115-129). Paris: Presses Universitaires de France.

Premack, D. (1976). Intelligence in ape and man. Hillsdale, NJ: Erlbaum Associates.

Premack, D. (1978). On the abstractness of human concepts: Why it would be difficult to talk to a pigeon. In S. Hulse, H. Fowler, \& W. K. Honig (Eds.), Cognitive processes in animal behavior (pp. 423-451). Hillsdale, NJ: Erlbaum.

Premack, D. (1983). The codes of man and beast. Behavioral and Brain Sciences, 6, 125-137.

Premack, D. (1988). Minds with and without language. In L. Weiskrantz (ED.), Thought without language (pp. 46-65). New York, NY: Oxford University Press.

Premack, A. J., \& Premack, D. (1972). Teaching language to an ape. Scientific American, 227, 92-99.

Quine, W. V. (1969). Natural kinds. In N. Rescher (Ed.), Essays in honor of Carl G. Hempel (pp. 5-23). Dordrecht, Holland: D. Reidel.

Rattermann, M. J., \& Gentner, D. (1998). The use of relational labels improves young children's performance in a mapping task. In K. Holyoak, D. Gentner, \& B. Kokinov (Eds.) Advances in analogy research: Integration of theory and data from the cognitive, computational, and neural sciences. (pp. 274-282). Sofia, Bulgaria: New Bulgarian 
University.

Richards, R. W. (1988). The question of bidirectional associations in pigeons' learning of conditional discrimination tasks. Bulletin of the Psychonomic Society, 26, 577-579.

Roberts, W. A., \& Mazmanian, D. S. (1988). Concept learning at different levels of abstraction by pigeons, monkeys, and people. Journal of Experimental Psychology: Animal Behavior Processes, 14, 247-260. doi:10.1037/0097-7403.14.3.247

Roberts, W. A., \& Phelps, M. T. (1994). Transitive inference in rats: A test of the spatial coding hypothesis. Psychological Science, 5, 368-374. doi:10.1111/j.1467-9280.1994.tb00287.x

Rodewald, H. K. (1974). Symbolic matching-to-sample by pigeons. Psychological Reports, 34, 987-990.

Rogers, L. J., \& Kaplan, G. (Eds.) (2004). Comparative Vertebrate Cognition Are Primates Superior to Non-Primates? Kluwer Academic/Plenum Publishers.

Roitblat, H. L., \& Meyer, J.-M. (1995). Comparative approaches to cognitive science. Cambridge MA: MIT Press.

Sands, S. F., Lincoln, C. E., \& Wright, A. A. (1982). Pictorial similarity judgments and the organization of visual memory in the rhesus monkey. Journal of Experimental Psychology: General, 111, 369-389.

doi:10.1037/0096-3445.111.4.369

Savage-Rumbaugh, E. S. (1986). Ape language: From conditioned response to symbol. New York, NY: Columbia University Press.

Savage-Rumbaugh, E. S., Rumbaugh, D. M., Smith, S. T., \& Lawson, J. (1980). Reference: The linguistic essential. Science, 210, 922-925. doi:10.1126/science.7434008

Schank, R. C., Collins, G. C., \& Hunter, L. E. (1986). Transcending inductive category formation in learning. Behavioral and Brain Sciences, 9, 639-651.

Schrier, A. M., \& Brady, P. M. (1987). Categorization of natural stimuli by monkeys (Macaca mulatta): Effects of stimulus set size and modification of exemplars. Journal of Experimental Psychology: Animal Behavior Processes, 13, 136-143. doi:10.1037/0097-7403.13.2.136

Schusterman, R. J., \& Kastak, C. R. (1993). A California sea lion (Zalophus californianus) is capable of forming equivalence relations. Psychological Record, 43, 823-839.

Shannon, C. E., \& Weaver, W. (1949). The mathematical theory of communications. Urbana, IL: University of Illinois Press.

Shettleworth, S. J. (1998). Cognition, evolution, and behavior. New York, NY: Oxford University Press.

Sidman, M. (1971). Reading and auditory-visual equivalences. Journal of Speech and Hearing Research, 14, 5-13.

Sidman, M. (1990). Equivalence relations: Where do they come from? In D. E. Blackman \& H. Lejeune (Eds.), Behaviour analysis in theory and practice: Contributions and controversies (pp. 93-114). Hillsdale, NJ: Erlbaum.

Sidman, M., \& Tailby, W. (1982). Conditional discrimination vs. matching-to-sample: An expansion of the testing paradigm. Journal of the Experimental Analysis of Behavior, 37, 5-22. ㅇi:10.1901/jeab.1982.37-5

Siegler, R. S., \& Crowley, K. (1992). Microgenetic methods revisited. American Psychologist, 47, 1241-1243. doi:10.1037/0003-066X.47.10.1241

Siemann, M., \& Delius, J. D. (1998). Algebraic learning and neural network models for transitive and non-transitive responding. European Journal of Cognitive Psychology, 10, 307-334. doi:10.1080/713752279

Smith, E. E., \& Medin, D. L. (1981). Categories and concepts. Cambridge, MA: Harvard University Press.

Smith, H. J., King, J. E., Witt, E. D., \& Rickel, J. E. (1975). Sameness-difference matching from sample by chimpanzees. Bulletin of the Psychonomic Society, 6, 469-471.

Spence, K. W. (1937). The differential response in animals to stimuli varying within a single dimension. Psychological Review, 44, 430-444. 이:10.1037/h0062885

Spinozzi, G. (1993). Development of spontaneous classificatory behavior in chimpanzees (Pan troglodytes), Journal of Comparative Psychology, 107, 193-200.

doi:10.1037/0735-7036.107.2.193

Spinozzi, G., Lubrano, G., \& Truppa, V. (2004). Categorization of above and below spatial relations by tufted capuchin monkeys (Cebus apella). Journal of Comparative Psychology, 118, 403-412. doi:10.1037/0735-7036.118.4.403

Staddon, J. E. R. (1983). Adaptive behavior and learning. Preface p. xii. New York, NY: Cambridge University Press.

Steirn, J. N., Weaver, J. E., \& Zentall, T. R. (1995). Transitive inference in pigeons: Simplified procedures and a test of value transfer theory. Animal Learning \& Behavior, 23, 76-82.

Sternberg, R. J. (1977). Intelligence, information processing, and analogical reasoning. Hillsdale, NJ: Lawrence Erlbaum.

Sternberg, R., \& Kaufman, J. (2002). The Evolution of Intelligence. Mahwah, NJ: Erlbaum.

Stromer, R., and MacKay, H. (1996). Naming and the formation of stimulus classes. In T. R. Zentall, \& P. M. Smeets (Eds.), Stimulus class formation in humans and animals (pp. 221-252). Amsterdam: Elsevier.

doi:10.1016/S0166-4115(06)80111-1

Thompson, R. K. R. (1995). Natural and relational concepts in animals. In H. Roitblat, \& J. A. Meyer (Eds.), Comparative approaches to cognitive science, Cambridge, MA: Bradford, MIT Press.

Thompson, R. K. R., \& Oden, D. L. (1993). "Language training" and its role in the expression of tacit propositional knowledge in chimpanzees (Pan troglodytes). In $\mathrm{H}$. L. Roitblat, L. M. Herman, \& P. E. Nachtigall (Eds.), Lan- 
guage and communication: Comparative perspectives, $\mathrm{pp}$. 365-384. Hillsdale, N J: Erlbaum.

Thompson, R. K. R., \& Oden, D. L. (1996). A profound disparity revisited: Perception and judgment of abstract identity relations by chimpanzees, human infants, and monkeys. Behavioural Processes (Special Issue: Cognition \& Evolution), 35, 149-161.

Thompson, R. K. R., \& Oden, D. L. (2000). Categorical perception and conceptual judgments by nonhuman primates: The paleological monkey and the analogical ape. Cognitive Science, 24, 363-396. (Special issue on primate cognition; Guest editor, M. Tomasello).

Thompson, R. K. R., Oden, D. L., \& Boysen, S. T. (1997). Language-naive chimpanzees (Pan troglodytes) judge relations-between-relations in an conceptual matching task. Journal of Experimental Psychology: Animal Behavior Processes, 23, 31-43. doi:10.1037/0097-7403.23.1.31

Thompson, R. K. R., Oden, D. L., \& Washburn, D. A. (in preparation). Conditional cues for relations of identity and nonidentity fail to enable analogical matching of relations in macaque monkeys (Macaca mulatta): Conditional stimuli do not function as symbols.

Tomasello, M., \& Call, J. (1997). Primate Cognition. New York, NY: Oxford University Press

Tyrrell, D. J., Stauffer, L. B., \& Snowman, L. G. (1991). Perception of abstract identity/difference relationships by infants. Infant Behavior and Development, 14, 125-129. doi:10.1016/0163-6383(91)90059-2

Tyrrell, D. J., Zingaro, M. C., \& Minard, K. L. (1993). Learning and transfer of identity-difference relationships by infants. Infant Behavior and Development, 16, 43-52. doi:10.1016/0163-6383(93)80027-6

Urcuioli, P. J. (1996). Acquired equivalences and mediated generalization in pigeon's matching-to-sample. In T. R. Zentall, \& P. M. Smeets (Eds.), Stimulus class formation in humans and animals (pp. 55-70). Amsterdam: North Holland. doi:10.1016/S0166-4115(06)80103-2

Urcuioli, P. J., Zentall, T. R., Jackson-Smith, P., \& Steirn, J. N. (1989). Evidence for common coding in many-to-one matching: Retention, intertrial interference, and transfer. Journal of Experimental Psychology: Animal Behavior Processes, 15, 264-273. doi:10.1037/0097-7403.15.3.264

Vauclair, J. (1996). Animal cognition: An introduction to modern comparative psychology. Cambridge, MA: Harvard University Press.

Vaughan, W., Jr. (1988). Formation of equivalence sets in pigeons. Journal of Experimental Psychology: Animal Behavior Processes, 14, 36-42.

doi:10.1037/0097-7403.14.1.36

Vogels, R. (1999). Categorization of complex visual images by rhesus monkeys. Part 1: behavioural study. European Journal of Neuroscience, 11, 1223-1238. doi:10.1046/j.1460-9568.1999.00530.x
Vonk, J., \& McDonald, S. E. (2002). Natural concepts in a juvenile gorilla (Gorilla gorilla gorilla) at three levels of abstraction. Journal of Experimental Analysis of Behavior, 78, 315-332. doi:10.1901/jeab.2002.78-315

Vonk, J., \& McDonald, S. E. (2004). Levels of abstraction in orangutan (Pongo abelii) categorization. Journal of Comparative Psychology, 118, 3-13. doi:10.1037/0735-7036.118.1.3

Washburn, D. A., Thompson, R. K. R., \& Oden D. L. (1997). Monkeys trained with same/different symbols do not match relations. Paper presented at the 38th Annual Meeting of the Psychonomic Society, Philadelphia, PA.

Wasserman, E. A. (1995). The conceptual abilities of pigeons. American Scientist, 83, 246-255.

Wasserman, E. A., \& Bhatt, R. S. (1992). Conceptualization of natural and artificial stimuli by pigeons. In W. K. Honig and J. G. Fetterman (Eds.), Cognitive aspects of stimulus control (pp. 203-223). Hillsdale, NJ: Erlbaum.

Wasserman, E. A., DeVolder, C. L., \& Coppage, D. J. (1992). Non-similarity based conceptualization in pigeons via secondary or mediated generalization. Psychological Science, 6, 374-379. doi:10.1111/j.1467-9280.1992.tb00050.x

Wasserman, E. A., Fagot, J., \& Young, M. E. (2001). Samedifferent conceptualization by baboons (Papio papio): The role of entropy. Journal of Comparative Psychology, 115, 42-52. $\quad$ doi:10.1037/0735-7036.115.1.42

Wasserman, E. A., Hugart, J. A., \& Kirkpatrick-Steger, K. (1995). Pigeons show same-different conceptualization after training with complex visual stimuli. Journal of Experimental Psychology: Animal Behavior Processes, 21, 248-252. doi:10.1037/0097-7403.21.3.248

Wasserman, E. A., \& Rovee-Collier, C. (2001). Conceptualization by infants and pigeons. In M. E. Carroll and J. B. Overmier (Eds.), Animal research and human health: Advancing human welfare through behavioral science (pp. 263-279). Washington, DC: American Psychological Association. doi:10.1037/10441-017

Wasserman, E. A., Young, M. E., \& Cook, R. G. (2004). Variability discrimination in humans and animals: Implications for adaptive action. American Psychologist, 59, 879-890. doi:10.1037/0003-066X.59.9.879

Wasserman, E. A., Young, M. E., \& Fagot, J. (2001 ). Effects of number of items on the baboon's discrimination of same from different visual displays. Animal Cognition, 4, 163-170. doi:10.1007/s100710100095

Wasserman, E. A., Young, M. E., \& Nolan, B. C. (2000). Display variability and spatial organization as contributors to the pigeons discrimination of complex visual stimuli. Journal of Experimental Psychology: Animal Behavior Processes, 26, 133-143. doi:10.1037/0097-7403.26.2.133 Wasserman, E. A., \& Zentall, T. R. (2006). Comparative cognition: Experimental explorations of animal intelligence. London: Oxford University Press. 
Weaver, J. E., Dorrance, B. R., \& Zentall, T. R. (1999). Present/absent sample matching in pigeons: Is comparison choice controlled by the sample stimulus or by differential sample responding? Animal Learning \& Behavior, 27, 288-294.

Weaver, J. E., Steirn J. N., \& Zentall, T. R. (1997). Transitive inference in pigeons: Control for differential value transfer. Psychonomic Bulletin \& Review, 4, 113-117.

Wilson, B., \& Boakes, R. A. (1985). A comparison of the short-term memory performance of pigeons and jackdaws. Animal Learning \& Behavior, 13, 285-290.

Wright, A. A., \& Katz, J. S. (2006). Mechanisms of same/ different concept learning in primates and avians. Behavioural Processes, 72, 234-254.

doi:10.1016/j.beproc.2006.03.009

Wright, A. A., Cook, R. G., Rivera, J. J., Sands, S. F., \& Delius, J. D. (1988). Concept learning by pigeons: Matchingto-sample with trial unique video picture stimuli. Animal Learning \& Behavior, 16, 436-444.

Wright, A. A., Rivera, J. J., Katz, J. S., \& Bachevalier, J. (2003). Abstract-concept learning and list-memory processing by capuchin and rhesus monkeys. Journal of Experimental Psychology: Animal Behavior Processes, 29, 184-198. doi:10.1037/0097-7403.29.3.184

Wynne, C. D. L. (1997). Pigeon transitive inference: Tests of simple accounts of a complex performance. Behavioural Processes, 39, 95-112. doi:10.1016/S0376-6357(96)00048-4

Wynne, C. D. L. (2001). Animal cognition: The mental lives of animals. New York, NY: Palgrave.

Yamamoto, J., \& Asano, T. (1995). Stimulus equivalence in a chimpanzee (Pan troglodytes). Psychological Record, 45, 3-21.

Yoshikubo, S. (1985). Species discrimination and concept formation by rhesus monkeys (Macaca mulatta). Primates, 26, 285-299. doi:10.1007/BF02382403

Young, M. E., \& Wasserman, E. A. (1997). Entropy detection by pigeons: Response to mixed visual displays after samedifferent discrimination training. Journal of Experimental Psychology: Animal Behavior Processes, 23, 157-170. doi:10.1037/0097-7403.23.2.157

Young, M. E., \& Wasserman, E. A. (2001). Entropy and variability discrimination. Journal of Experimental Psychology: Learning, Memory, and Cognition, 27, 278-293. doi:10.1037/0278-7393.27.1.278

Young, M. E., \& Wasserman, E. A. (2002). Detecting variety: What's so special about uniformity? Journal of Experimental Psychology: General, 131, 131-143. doi:10.1037/0096-3445.131.1.131

Young, M. E., Wasserman, E. A., \& Dalrymple, R. M. (1997). Memory-based same-different conceptualization by pigeons. Psychonomic Bulletin \& Review, 4, 552-558. Young, M. E., Wasserman, E. A., \& Garner, K. L. (1997).
Effects of number of items on the pigeon's discrimination of same from different visual displays. Journal of Experimental Psychology: Animal Behavior Processes, 23, 491501. doi:10.1037/0097-7403.23.4.491

Zentall, T. R. (1996). An analysis of stimulus class formation in animals. In T. R. Zentall \& P. M. Smeets (Eds.), Stimulus class formation in humans and animals (pp.1534). Amsterdam: North-Holland. doi:10.1016/S0166-4115(06)80101-9

Zentall, T. R., Clement, T. S., \& Weaver, J. E. (2003). Symmetry training in pigeons can produce functional equivalences. Psychonomic Bulletin \& Review, 10, 387-391.

Zentall, T. R., Edwards, C. A., Moore, B. S., \& Hogan, D. E. (1981). Identity: The basis for both matching and oddity learning in pigeons. Journal of Experimental Psychology: Animal Behavior Processes, 7, 70-86.

doi:10.1037/0097-7403.7.1.70

Zentall, T. R., Galizio, M., \& Critchfield, T. S. (2002). Categorization, concept learning, and behavior analysis: An introduction. Journal of the Experimental Analysis of Behavior, 78, 237-248. doi:10.1901/jeab.2002.78-237

Zentall, T. R., \& Hogan, D. E. (1976). Pigeons can learning identity, difference, or both. Science, 191, 408-409. doi:10.1126/science.191.4225.408

Zentall, T. R., Kaiser, D. H., Clement, T. S., Weaver, J. E., \& Campbell, G. (2000). Presence/absence-sample matching by pigeons: Divergent retention functions may result from the similarity of behavior during the absence sample and the retention interval. Journal of Experimental Psychology: Animal Behavior Processes, 26, 294-304. doi:10.1037/0097-7403.26.3.294

Zentall, T. R., Sherburne, L. M., \& Urcuioli, P. J. (1995). Coding of hedonic and nonhedonic samples by pigeons in many-to-one delayed matching. Animal Learning \& Behavior, 23, 189-196.

Zentall, T. R., Urcuioli, P. J., Jagielo, J. A., \& Jackson-Smith, P. (1989). Interaction of sample dimension and samplecomparison mapping on pigeons' performance of delayed conditional discriminations. Animal Learning \& Behavior, 17, 172-178. 